\title{
CONTRIBUIÇÕES DAS PESQUISAS EM ENSINO DE CIÊNCIAS E MATEMÁTICA ATINENTES À PRODUÇÃO ESCRITA
}

\section{CONTRIBUTIONS OF RESEARCH IN SCIENCE AND MATHEMATICS TEACHING RELATED TO WRITTTEN PRODUCTION}

\author{
Jeferson Ferreti Ribas ${ }^{1}$
}

\author{
Fabiele Cristiane Dias Broietti ${ }^{2}$
}

\begin{abstract}
Resumo: Neste artigo apresentamos resultados de uma pesquisa de caráter bibliográfico, com a intenção de conhecer as investigações atinentes à produção escrita (PE) presentes em trabalhos acadêmicos da área de Ensino de Ciências e Matemática. Com o intuito de identificar em que contexto de investigação a produção escrita foi empregada e como os autores desses trabalhos compreendem o termo produção escrita, utilizamos os procedimentos metodológicos da Análise de Conteúdo para selecionar e analisar 65 Dissertações e 17 Teses. Como resultados, evidenciamos que as pesquisas em Ensino de Ciências e Matemática utilizaram a produção escrita como instrumento de aprendizagem ou como instrumento formativo, uma vez que objetivaram investigar os conhecimentos mobilizados pelos sujeitos que realizaram a PE ou estiveram relacionadas à aprendizagem docente dos sujeitos que analisaram ou realizaram a PE. Constatamos, também, que a produção escrita apresentada nesses trabalhos acadêmicos consistiu em registros escritos, desenhos, representações geométricas, colagens e resoluções matemáticas.
\end{abstract}

Palavras-chave: Produção escrita; Pesquisas acadêmicas; Ensino de Ciências e Matemática.

\begin{abstract}
In this article, we present results of a bibliographic research with the intention of knowing the investigations related to the written production in academic research in the area of Science and Mathematics Teaching. In order to identify in which research context was employed the written production and how the authors of these works understood written production, we used the methodological procedures of Content Analysis to select and analyze 65 Dissertations and 17 Theses. As a result, we found that research in Science and Mathematics Teaching used written production as a learning tool or as a training tool, since they investigated the knowledge mobilized by the subjects who carried out the written production, or were related to the teaching learning of the subjects who analyzed or carried out the written production. We also verified that the written production presented in these academic works consisted of written records, drawings, geometric representations, collages and mathematical resolutions.
\end{abstract}

Keywords: Written production; Academic research; Science and Mathematics Teaching.

\footnotetext{
${ }^{1}$ Mestre em Ensino de Ciências e Educação Matemática, Universidade Estadual de Londrina (UEL). Doutorando em Ensino de Ciências e Educação Matemática, Universidade Estadual de Londrina (UEL), Londrina, Paraná, Brasil. E-mail: jferretiribas@gmail.com.

${ }^{2}$ Doutora em Educação para a Ciência e o Ensino de Matemática, Universidade Estadual de Maringá (UEM). Docente Adjunta da Universidade Estadual de Londrina (UEL), Londrina, Paraná, Brasil. E-mail: fabieledias@uel.br.
} 


\section{Introdução}

Nas últimas duas décadas, pesquisas no campo da Educação Matemática (ALVES, 2006; CELESTE, 2008; LOPEZ, 2010; PEDROCHI JUNIOR, 2012; SANTOS, 2014) têm apontado para uma avaliação da aprendizagem como prática de investigação caracterizada por possibilitar ao professor certificar, regular e orientar a aprendizagem dos estudantes e repensar seu ensino, por meio da análise da produção escrita.

Estas pesquisas ressaltam a importância que a produção escrita (PE) possui na perspectiva da avaliação enquanto prática de investigação em sala de aula e oportunidade de ensino e aprendizagem, uma vez que pode permitir ao professor compreender como os alunos interpretam e conduzem as estratégias e procedimentos adotados nas resoluções, por exemplo, de questões utilizadas em uma prova, trabalho ou atividade, demonstrando o que sabem, bem como revelam as suas dificuldades. Em outras palavras, ao investigar a produção escrita dos estudantes, pode ser possível conhecer "como e o que" está sendo ensinado e, "como e o que" o aluno está aprendendo (CELESTE, 2008), possibilitando orientar o professor na tomada de decisões frente aos processos de ensino e de aprendizagem.

Apesar de utilizada e discutida em inúmeras pesquisas da Educação Matemática, estudos que analisam a produção escrita apresentam pouca expressividade em pesquisas da área de Ensino de Ciências e, desse modo, estendem possibilidades de investigações a serem realizadas também por pesquisadores desta área.

Nossas intenções futuras de investigação perpassam pela análise da produção escrita realizada por estudantes em questões da área de Ciências da Natureza, especificamente relacionadas à área de Química, como o apresentado em Ribas e Broietti (2020), no qual os autores analisam a produção escrita de estudantes do Ensino Médio em questões de Ciências que abordam conceitos químicos, presentes na avaliação educacional em larga escala PISA (Programme for International Student Assessment Programa Internacional de Avaliação de Estudantes). Nesse sentido, optamos por realizar uma pesquisa exploratória a respeito do tema para conhecer, no cenário das pesquisas nacionais em Ensino de Ciências e Matemática, investigações atinentes à produção escrita.

Neste artigo, apresentamos resultados de uma investigação de caráter bibliográfico, compreendendo Teses e Dissertações da área de Ensino de Ciências e 


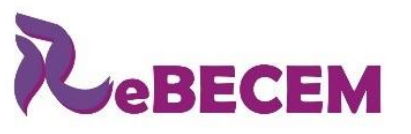

Revista Brasileira de Educação em

Ciências e Educação Matemática

DOI: https://doi.org/10.33238/ReBECEM.2021.v.5.n.2.27241

Matemática, com o objetivo de identificar (i) em que contexto de investigação a produção escrita é empregada e (ii) como os autores desses trabalhos compreendem produção escrita.

A seguir, elucidamos algumas considerações atinentes à produção escrita e, na sequência, apresentamos o percurso metodológico seguido dos resultados e algumas considerações finais relativas à investigação das contribuições das pesquisas em Ensino de Ciências e Matemática que versam sobre produção escrita.

\section{Considerações iniciais atinentes à produção escrita}

As pesquisas mencionadas na seção introdutória deste artigo fazem parte de inúmeras investigações desenvolvidas no âmbito do grupo de pesquisa GEPEMA ${ }^{3}$ e pautaram-se: na análise da produção escrita realizada por estudantes da Educação Básica (Ensinos Fundamental e Médio) em questões de Matemática com o intuito de conhecer, em geral, como os estudantes lidam com essas questões em situação de prova (ALVES, 2006; CELESTE, 2008; LOPEZ, 2010); e, em dois estudos de caráter bibliográfico relacionados à avaliação escolar como oportunidade de aprendizagem (PEDROCHI JUNIOR, 2012) e utilização da análise da produção escrita como estratégia de avaliação para investigar os processos de ensino e de aprendizagem da Matemática (SANTOS, 2014).

As produções escritas que aparecem nessas investigações consistem nas resoluções dos sujeitos em questões de Matemática. A expressão produção escrita é vista por Pereira e Dalto $(2019$, p. 7) e por uma parcela de outros pesquisadores no âmbito do GEPEMA “[...] como sendo todas as representações escritas (desenhos, gráficos e textuais) realizadas pelos alunos ao explicitarem seus entendimentos de conceitos ou apresentarem soluções para situações-problema".

Pesquisas relacionadas ao ensino da Língua Portuguesa associam a ideia de produção escrita aos termos produção textual, produção de texto escrito, produção de gêneros discursivos e redações (BARRERA; SANTOS, 2016; LIMA; FERRETTISOARES; SILVEIRA, 2015; NOGARO; PORTO; PORTO, 2019). Nestas perspectivas,

\footnotetext{
${ }^{3}$ GEPEMA - Grupo de Estudos e Pesquisa em Educação Matemática e Avaliação, Programa de PósGraduação em Ensino de Ciências e Educação Matemática, Universidade Estadual de Londrina.
} 
DOI: https://doi.org/10.33238/ReBECEM.2021.v.5.n.2.27241

podemos dizer que a produção escrita se relaciona diretamente ao ato de escrever, de expressar-se por meio da escrita.

No que se refere às áreas Ciências da Natureza e Matemática, pesquisas baseadas nos referenciais semióticos da multimodalidade representacional e na teoria de Duval (2004) ressaltam que os discursos científico e matemático apresentam diferentes formas de representações e, nesse sentido, a aprendizagem de conceitos das Ciências e da Matemática envolve a capacidade do sujeito em mobilizar diversas formas representacionais, as múltiplas representações ${ }^{4}$ (BONI; LABURÚ; CAMARGO FILHO, 2018; HENRIQUES; PONTE, 2014; KLEIN; LABURÚ, 2012). Uma equação matemática, por exemplo, pode ser representada na forma de registro algébrico, gráfico ou em linguagem natural (LABURÚ; BARROS; SILVA, 2011); no ensino de Função do $1^{\circ} \mathrm{Grau}$, os registros de representação mais comumente utilizados são os algébricos, em língua natural escrito, gráfico, tabular e imagético (LABURÚ; FARIA, 2018); no ensino de conceitos químicos, as representações para átomos, moléculas, fórmulas e equações químicas, transformações e mecanismos de reações podem se apresentar na forma escrita em linguagem natural, desenhos, gráficos, tabelas, esquemas, imagens (WARTHA; REZENDE, 2017).

Todas as áreas do conhecimento possuem seus processos de representação. De acordo com a Base Nacional Comum Curricular (BNCC), os registros de representação nas Ciências da Natureza estão associados a procedimentos e a linguagens próprias da área e podem ocorrer por meio de símbolos, códigos, nomenclaturas e gêneros textuais, constituindo o processo de Letramento Científico necessário a todo cidadão. Os registros algébricos, geométricos, estatísticos, computacionais, gráficos, em tabelas, em forma de esquemas, textos escritos na língua materna e textos em outras linguagens para descrever algoritmos e dados, compõem os diferentes registros de representação matemáticos e podem ser utilizados para solucionar e comunicar resultados em inúmeras situações. Tratam-se de representações mobilizadas por diversas áreas do conhecimento, como as Ciências da Natureza e a Matemática (BRASIL, 2018).

Diante do exposto, inferimos que a produção escrita em Ensino de Ciências e Matemática pode contemplar não somente os aspectos representacionais apresentados por Pereira e Dalto (2019). Nesse sentido, considerando a presente investigação de caráter

\footnotetext{
4 Múltiplas representações "refere-se à prática de representar um mesmo conceito de várias formas diferentes” (LABURÚ; BARROS; SILVA, 2011, p. 472).
} 
DOI: https://doi.org/10.33238/ReBECEM.2021.v.5.n.2.27241

bibliográfico, a BNCC e os referenciais relacionados às múltiplas representações, após apresentar os resultados deste estudo tentaremos propor uma definição de produção escrita para a área de Ensino de Ciências e Matemática.

\section{Percurso metodológico para investigar as contribuições das pesquisas em Ensino de Ciências e Matemática atinentes à produção escrita}

Para conhecer as pesquisas relacionadas à produção escrita, realizamos um mapeamento das produções científicas da área de Ensino de Ciências e Matemática por meio da consulta em dois bancos de dados nacionais, a saber: Catálogo de Teses e Dissertações da CAPES $^{5}$ (Coordenação de Aperfeiçoamento de Pessoal de Nível Superior) e IBICT $^{6}$ (Instituto Brasileiro de Informação em Ciência e Tecnologia), uma vez que tais plataformas possuem reunidas as principais pesquisas desenvolvidas no âmbito dos Programas de Pós-Graduação do Brasil (STANZANI, 2018).

A presente investigação, de caráter bibliográfico, é denominada "Estado da Arte" ou "Estado do Conhecimento" (FERREIRA, 2002), e pode ser desenvolvida a partir de Artigos Científicos, Anais de Congressos, Teses e Dissertações, em que se busca apresentar, analisar e/ou discutir elementos sobre determinado conhecimento e produção acadêmica em diferentes épocas e lugares, bem como prover indícios para as fundamentações teórica e metodológica de uma investigação (FERREIRA, 2002; GIL, 2017).

Inicialmente realizamos uma pré-seleção de produções científicas, em que constam Teses e Dissertações, por meio dos diretórios da CAPES e IBICT, buscando escolher, a partir da leitura dos títulos, palavras-chave e resumos, as pesquisas relacionados ao Ensino de Ciências e Matemática que integrassem elementos da produção escrita, como por exemplo, investigações pautadas na análise da produção escrita, ou investigações em que a produção escrita constituísse um dos instrumentos para a coleta e análise de informações da pesquisa.

No Catálogo de Teses e Dissertações do Portal CAPES, a busca foi iniciada utilizando o termo "Produção Escrita". Por meio desse movimento, foram encontrados

\footnotetext{
${ }^{5}$ Disponível em: <http://catalogodeteses.capes.gov.br/catalogo-teses/\#!/>. Acesso em: 07 abr. 2021.

${ }^{6}$ Disponível em: <http://bdtd.ibict.br/vufind/>. Acesso em: 07 abr. 2021.
} 
DOI: https://doi.org/10.33238/ReBECEM.2021.v.5.n.2.27241

1470 trabalhos acadêmicos, dentre eles, 271 Teses e 1199 Dissertações. Na sequência, utilizamos o filtro ‘Área do Conhecimento', em que foram selecionadas, separadamente, as áreas: Ensino, Ensino de Ciências e Matemática, Biologia, Ciências, Física, Matemática e Química, resultando em 94 produções acadêmicas, publicadas entre os anos de 2007 e 2019, selecionadas para uma próxima etapa da investigação. Deste total, obtivemos 27 trabalhos selecionados por meio do filtro Ensino, 63 provenientes do filtro Ensino de Ciências e Matemática, dois selecionados pelo filtro Matemática e, por fim, apenas um selecionado a partir dos filtros Física e Química, cada. Cabe ressaltar que não foram encontrados trabalhos acadêmicos por meio dos filtros Biologia e Ciências.

Para a Biblioteca Digital Brasileira de Teses e Dissertações do IBICT, a expressão "Produção Escrita" também foi utilizada como termo disparador da busca por trabalhos científicos. A partir desse movimento encontramos 170 Teses e 620 Dissertações, totalizando 790 produções. Por apresentar muitos trabalhos de áreas do conhecimento que não faziam parte do escopo desta investigação, optamos por usar um segundo termo de busca, realizado em cinco etapas:

$1^{\text {a }}$. Primeiramente, utilizamos os termos de busca "Produção Escrita" e "Ensino de Ciências", no qual foram encontrados 44 trabalhos científicos. Desse movimento, selecionamos apenas 11, uma vez que 33 deles já haviam sido selecionados a partir do Catálogo de Teses e Dissertações do Portal CAPES.

$2^{a}$. Na sequência, "Produção Escrita" e "Educação em Ciências" foram utilizados como termos de busca. Dentre os 9 trabalhos encontrados, apenas três tinham relação com a área de Ensino de Ciências e Matemática, em que dois já haviam sido escolhidos por meio da busca no Catálogo de Teses e Dissertações do Portal CAPES. Assim, apenas um trabalho acadêmico foi selecionado.

$3^{\text {a }}$. No movimento de busca seguinte, a partir dos termos "Produção Escrita" e "Educação Científica", encontramos três trabalhos, sendo dois deles selecionados anteriormente a partir do Catálogo de Teses e Dissertações do Portal CAPES. Assim, apenas um trabalho acadêmico foi selecionado.

$4^{\mathrm{a}}$. No quarto movimento de busca, foram utilizados os termos "Produção Escrita" e "Educação Matemática". Resultaram 38 trabalhos, dentre eles, 32 selecionados a partir do Catálogo de Teses e Dissertações do Portal CAPES e pelos três movimentos anteriores do IBICT. Nesse sentido, selecionamos 6 trabalhos acadêmicos por meio deste movimento.

5 . Por fim, utilizamos os termos "Produção Escrita" e "Ensino de Matemática", 


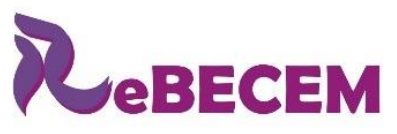

Revista Brasileira de Educação em

Ciências e Educação Matemática

DOI: https://doi.org/10.33238/ReBECEM.2021.v.5.n.2.27241

em que foram encontrados cinco trabalhos, dentre eles, quatro selecionados a partir do Catálogo de Teses e Dissertações do Portal CAPES e pelos quatro primeiros movimentos de busca no IBICT. Tivemos então, apenas um trabalho acadêmico selecionado.

Por meio das cinco etapas, movimentos de busca realizados na Biblioteca Digital Brasileira de Teses e Dissertações do IBICT, foram selecionados vinte trabalhos acadêmicos.

As buscas nos dois bancos de dados (CAPES e IBICT) seguiram passos distintos por apresentarem sistemas de busca diferentes.

Após a pré-seleção de Teses e Dissertações, tivemos como resultado um total de 114 trabalhos acadêmicos selecionados. Entretanto, a partir da leitura das referências de uma das Dissertações selecionadas no diretório de busca da CAPES, nos deparamos com duas outras produções acadêmicas, relacionadas à análise da produção escrita e que não haviam sido localizadas pelas fontes de busca CAPES e IBICT. Assim, por meio desta busca independente, foram acrescidas as duas Dissertações ao acervo, totalizando 116 trabalhos acadêmicos, publicados entre os anos de 2005 e 2019.

Em uma etapa seguinte, realizamos a leitura das 116 Teses e Dissertações, a fim de se obter uma seleção mais criteriosa quanto às intenções do presente estudo, ou seja, como mencionado anteriormente, selecionar apenas os trabalhos que integrassem elementos relacionados à produção escrita (investigações pautadas na análise da produção escrita; ou a produção escrita como um dos instrumentos para a coleta e análise de informações da pesquisa).

Uma leitura mais detalhada nesses trabalhos científicos se fez necessária, uma vez que, em muitos deles, somente a partir do título, resumo e palavras-chave não foi possível selecioná-los de acordo com as intenções da investigação. Ferreira (2002) ressalta que a leitura na íntegra de trabalhos acadêmicos pode trazer confiabilidade às pesquisas Estado da Arte, pois as Teses e Dissertações podem apresentar resumos sucintos e/ou mal elaborados, não dando a ideia "verdadeiramente" dos aportes teóricos e metodológicos, resultados e considerações desses trabalhos, isto é, acabam não explicitando do que se trata a pesquisa.

A partir desse movimento de leitura, alguns trabalhos foram excluídos do acervo, uma vez que suas pesquisas não tinham relação com a área de Ensino de Ciências e Matemática ou não apresentavam investigações em que a produção escrita tenha sido utilizada como um dos instrumentos para a coleta e análise de informações. Desse modo, resultaram 82 Teses e Dissertações, 65 provenientes do diretório de busca da CAPES, 
DOI: https://doi.org/10.33238/ReBECEM.2021.v.5.n.2.27241

quinze provenientes do diretório de busca do IBICT e dois trabalhos incluídos por meio de uma busca independente.

Na tentativa de conhecer as pesquisas de Doutorado e Mestrado relacionadas à produção escrita realizadas na área de Ensino de Ciências e Matemática, utilizamos os procedimentos da Análise de Conteúdo (BARDIN, 2016) para selecionar, organizar, codificar, analisar e interpretar o corpus constituído pelas 82 produções acadêmicas. Os movimentos de seleção, organização e codificação dos trabalhos acadêmicos contemplaram a etapa de pré-análise prevista na Análise de Conteúdo.

As produções acadêmicas selecionadas para análise foram organizadas em uma planilha do excel® contendo informações do título do trabalho, autor(a), ano de publicação, nível da pesquisa (Doutorado ou Mestrado), instituição de ensino, área, Programa de Pós-Graduação e orientador(a). A codificação e a identificação foram realizadas de acordo com uma ordem numérica (que variou de 01 a 82), considerando o diretório de busca (CAPES ou IBICT) e o nível da pesquisa ("D" para Doutorado e "M" para Mestrado); por exemplo, 14_CAPES_M corresponde ao $14^{\circ}$ trabalho acadêmico, uma Dissertação de Mestrado selecionada por meio do diretório de busca do Catálogo de Teses e Dissertações do Portal CAPES. Os dois trabalhos selecionados por meio da busca independente receberam apenas a codificação numérica e do nível de pesquisa.

Em uma etapa seguinte, denominada exploração do material, realizamos um estudo aprofundado nos trabalhos acadêmicos. Mediante uma leitura inicial, elaboramos um documento no word® em que foram reunidas informações de cada produção acadêmica a respeito do(s) "Objetivo(s)", da "Abordagem Metodológica" e dos "Resultados e Considerações", além de aspectos relacionados à "Produção Escrita".

Por meio das informações do título da obra, autor(a), ano de publicação, nível da pesquisa (Mestrado ou Doutorado), instituição de ensino, área, Programa de PósGraduação e orientador(a) foi realizada uma análise a fim de se obter um panorama das pesquisas acadêmicas relacionadas à produção escrita na área de Ensino de Ciências e Matemática. As demais informações contidas nos trabalhos acadêmicos possibilitaram identificar: (i) em que contexto ${ }^{7}$ de investigação a produção escrita é empregada e (ii) como os autores desses trabalhos compreendem produção escrita.

Na continuidade, a fim de cumprir o primeiro objetivo da investigação, foram

\footnotetext{
${ }^{7}$ Nesta pesquisa, contexto refere-se àquilo que está atinente à produção escrita nos trabalhos acadêmicos inventariados. De acordo com a análise e interpretação dos dados, a produção escrita apareceu em um contexto de atividades em que os sujeitos realizaram ou analisaram PE.
} 
DOI: https://doi.org/10.33238/ReBECEM.2021.v.5.n.2.27241

agrupados elementos conforme características semelhantes em categorias emergentes, resultando no processo de categorização.

Conforme a última etapa que compreende o conjunto de técnicas da Análise de Conteúdo, realizamos o tratamento dos resultados por meio da interpretação das categorias, em um processo de descrição e inferência dos resultados brutos, pautados nos objetivos da investigação, na análise crítica e, também, segundo a intuição dos pesquisadores.

$\mathrm{Na}$ sequência, são apresentadas as descrições, inferências e interpretações provenientes da análise das 82 produções acadêmicas que apresentam aspectos relacionados à produção escrita.

\section{Um panorama das pesquisas nacionais envolvendo produção escrita no Ensino de Ciências e Matemática}

A análise das produções acadêmicas, que se referem às Teses e Dissertações, revelou informações significativas frente ao cenário das pesquisas nacionais em Ensino de Ciências e Matemática que versam sobre produção escrita. A seguir, apresentamos algumas considerações iniciais a fim de se obter um panorama dessas produções.

Dentre os 82 trabalhos selecionados para análise, constatou-se que 65 deles são Dissertações de Mestrado, enquanto 17 são Teses de Doutorado, publicados em um intervalo de 15 anos, no período de $2005-2019^{8}$, como mostra a Figura 1, a seguir.

\footnotetext{
${ }^{8}$ É importante ressaltar que as buscas por produções acadêmicas atinentes à produção escrita na área de Ensino de Ciências e Matemática foram finalizadas em 07 de abril de 2021, não tendo sido encontrado nenhum trabalho acadêmico anterior ao ano de 2005 e posterior ao ano de 2019.
} 
DOI: https://doi.org/10.33238/ReBECEM.2021.v.5.n.2.27241

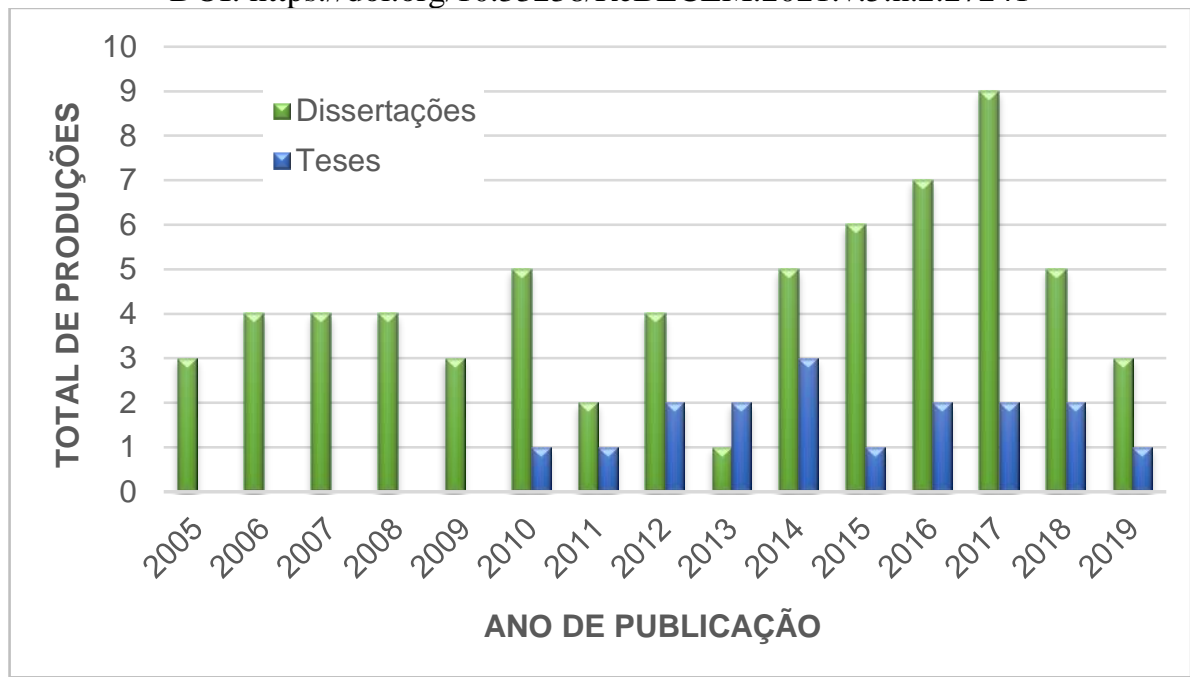

Figura 1: Quantidade de trabalhos acadêmicos que versam sobre produção escrita publicados no período de 2005-2019

Fonte: Os autores (2021).

O gráfico apresentado na Figura 1 refere-se à disseminação das produções acadêmicas anualmente, no qual podemos observar a publicação de apenas Dissertações no período compreendido entre os anos de 2005 e 2009, totalizando 18 trabalhos acadêmicos. A partir de 2010 começam a aparecer as primeiras Teses que versam sobre aspectos da produção escrita e, no período de 2010-2014, observamos um total de 26 trabalhos acadêmicos publicados (9 Teses e 17 Dissertações). Nos últimos 5 anos que abrangem o período de trabalhos selecionados, verificamos um aumento nas produções acadêmicas, compreendendo um total de 38 no período de 2015-2019, sendo 8 Teses e 30 Dissertações.

As 82 Teses e Dissertações apresentam pesquisas desenvolvidas na Educação Infantil, nos Ensinos Fundamental, Médio e Superior, e em cursos de nível técnico, envolvendo as áreas de Biologia, Ciências, Física, Matemática e Química, conforme o exposto na Figura 2, a seguir. 
DOI: https://doi.org/10.33238/ReBECEM.2021.v.5.n.2.27241

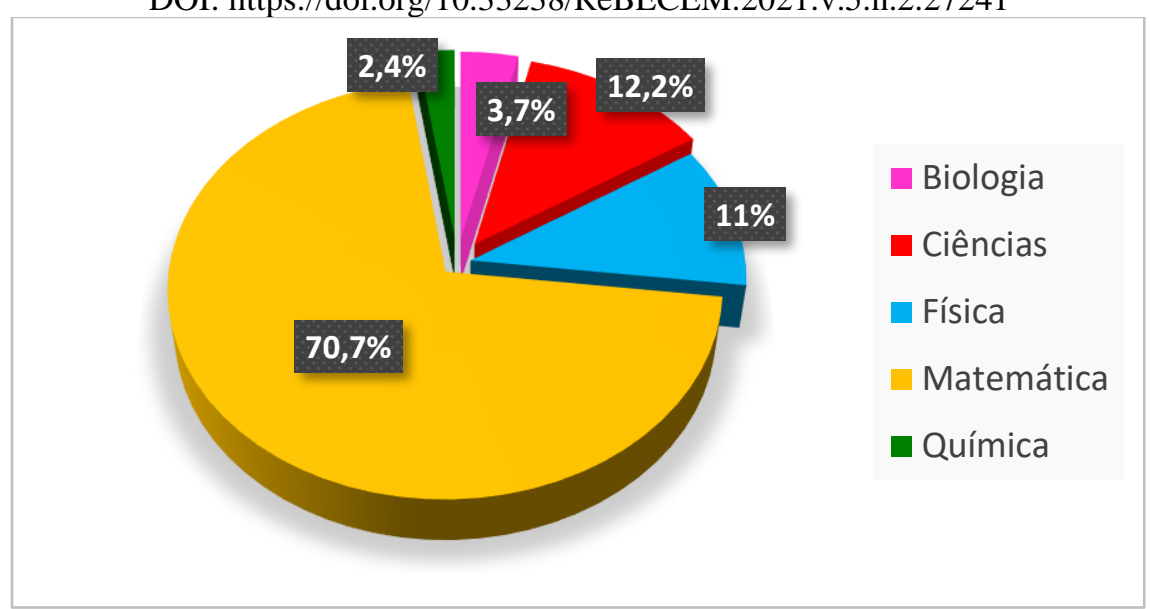

Figura 2: Distribuição percentual de trabalhos acadêmicos que versam sobre produção escrita por áreas das Ciências da Natureza e Matemática

Fonte: Os autores (2021).

No que tange à distribuição dos trabalhos acadêmicos por áreas das Ciências da Natureza e Matemática (Figura 2), verificamos que a Matemática abrange a maior quantidade de trabalhos relacionados à produção escrita, contando com 47 Dissertações e 11 Teses (58 produções acadêmicas), compreendendo 70,7\% do total de produções acadêmicas selecionadas neste estudo. A área de Ciências apresenta oito Dissertações e duas Teses, correspondendo a 12,2\% dos trabalhos. A Física conta com $11 \%$ das produções selecionadas, sendo seis Dissertações e três Teses. Três trabalhos - apenas Dissertações - pertencem à Biologia, e dois trabalhos à Química (uma Dissertação e uma Tese), representando $3,7 \%$ e 2,4\%, respectivamente, dentre as produções selecionadas.

$\mathrm{Na}$ continuidade das considerações relacionadas a um panorama geral das pesquisas nacionais em Ensino de Ciências e Matemática atinentes à produção escrita, as Figuras 3 e 4 apresentam, respectivamente, a distribuição das 82 produções acadêmicas no território brasileiro e em instituições de ensino.

As pesquisas que versam sobre produção escrita na área de Ensino de Ciências e Matemática têm sido realizadas em todo o Brasil (Figura 3), com destaque para a região Sul, que concentra mais da metade do total das produções - 56\% dos trabalhos acadêmicos (54\% das Dissertações e 65\% das Teses); seguida da região Sudeste, abarcando 25\% das produções (25\% das Dissertações; 29\% das Teses), e das regiões Centro-Oeste, Nordeste e Norte, contando com apenas 19\% dos trabalhos selecionados (21\% das Dissertações; $6 \%$ das Teses). 

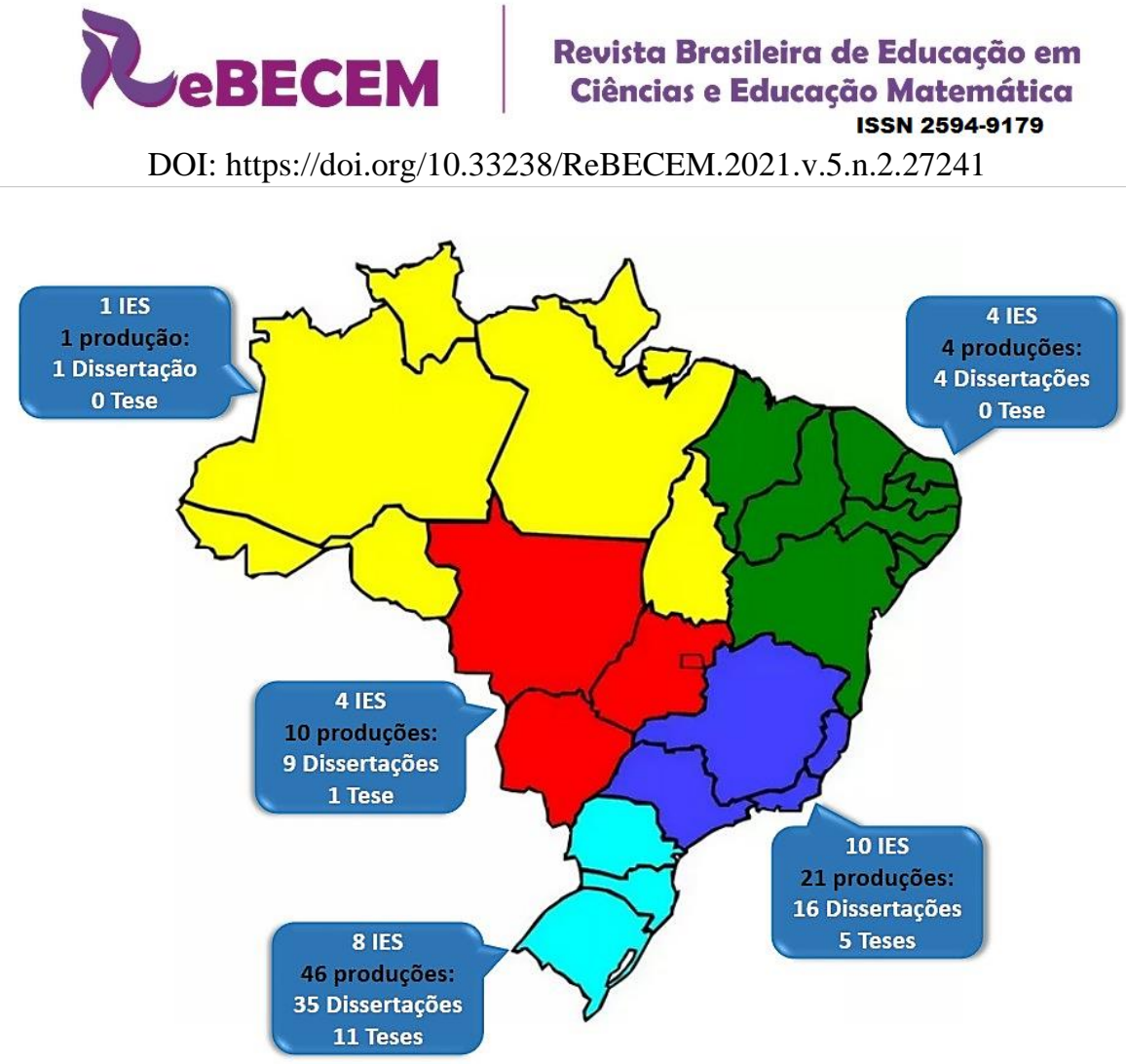

Figura 3: Distribuição de trabalhos acadêmicos que versam sobre produção escrita no território brasileiro IES: Instituição(ões) de Ensino Superior

Fonte: Mapa original - site Educa Mais Brasil ${ }^{9}$. Figura - Os autores (2021).

Essas produções estão vinculadas a Programas de Pós-Graduação presentes em 27 instituições de ensino que ofertam cursos de nível superior (sendo 25 instituições públicas - 76 produções - e duas instituições privadas - seis produções). É possível observar a expressiva produtividade na Universidade Estadual de Londrina (UEL) (Figura 4).

De acordo com as Figuras 3 e 4, os estados do Brasil que apresentam instituições de ensino com mais produções científicas atinentes à produção escrita são, em ordem crescente, Rio Grande do Sul (cinco Dissertações e uma Tese em três IES - FURG, PUCRS e UFRGS), Mato Grosso do Sul (seis Dissertações em uma IES - UFMS), São Paulo (doze Dissertações e cinco Teses em seis IES - PUCSP, UFABC, UFSCar, UNESP, UNICAMP e USP) e Paraná (29 Dissertações e nove Teses em quatro IES UEL, UFPR, UNIOESTE e UTFPR).

\footnotetext{
${ }^{9}$ Disponível em: <https://www.educamaisbrasil.com.br/enem/geografia/regioes-brasileiras>. Acesso em: 09 dez 2020.
} 


\section{QeBzсEM}

DOI: https://doi.org/10.33238/ReBECEM.2021.v.5.n.2.27241

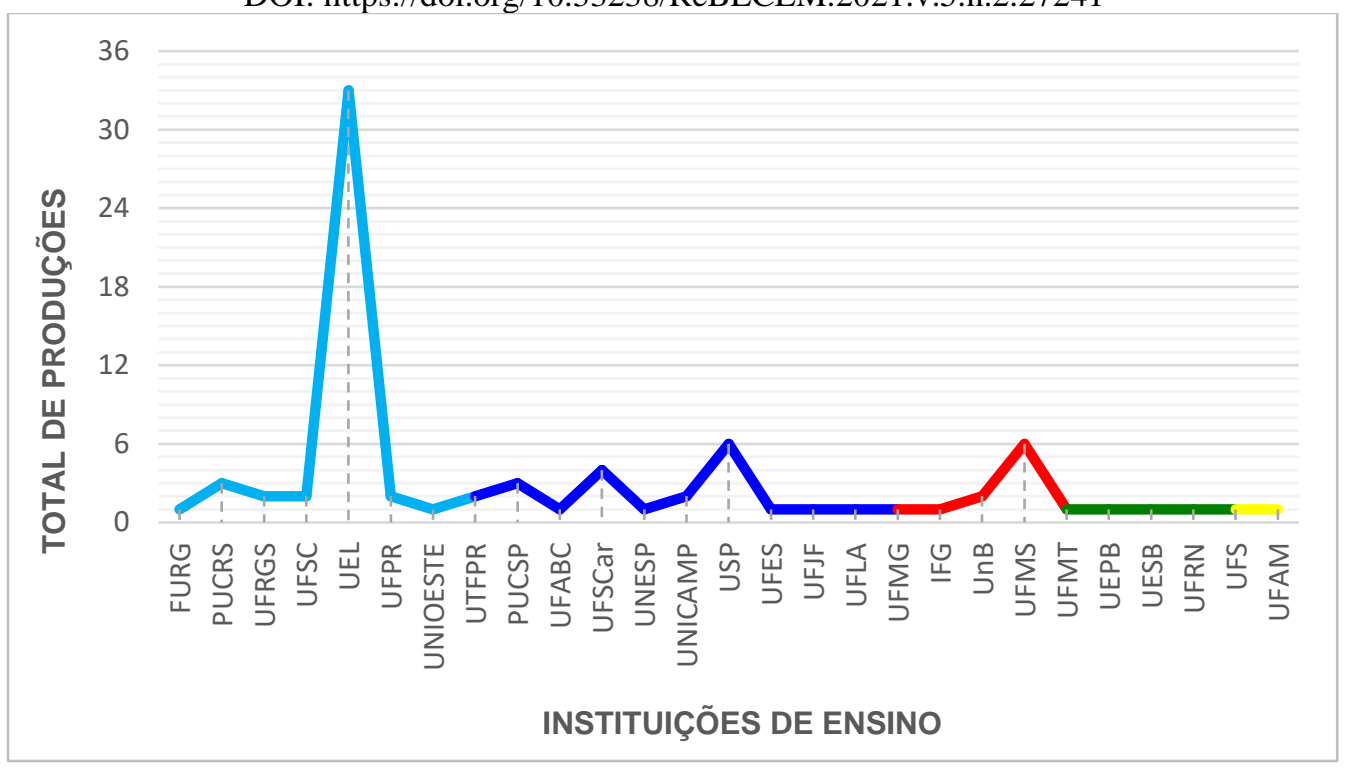

Figura 4: Instituições de ensino de origem das pesquisas que versam sobre produção escrita Fonte: Os autores (2021).

Entre os anos de 2005 e 2019, pesquisadores da UEL produziram 33 trabalhos científicos que versam sobre aspetos da produção escrita (Figura 4), apresentados ao Programa de Pós-Graduação em Ensino de Ciências e Educação Matemática (PECEM), dentre eles, 24 Dissertações relacionadas às áreas: Biologia (uma produção) e Matemática (23 produções); e nove Teses referentes às áreas: Ciências (uma produção) e Matemática (oito produções).

Dentre as 82 Teses e Dissertações constatamos 80 autorias, uma vez que dois autores apresentam um trabalho de Mestrado (13_CAPES_M e 03_CAPES_M) e de Doutorado (25_CAPES_D e 39_CAPES_D), cada. Esses 80 estudantes de Mestrado e Doutorado receberam a orientação de 44 professores das 27 instituições de ensino apresentadas na Figura 4, com destaque aos orientadores Angela Marta Pereira das Dores Savioli, com quatro orientações de Mestrado (UEL); João Ricardo Viola dos Santos, com seis orientações de Mestrado (UFMS); e Regina Luzia Corio de Buriasco, com 19 orientações de Mestrado e sete de Doutorado (UEL).

$\mathrm{Na}$ continuidade, as produções acadêmicas selecionadas foram analisadas a fim de identificarmos: (i) em que contexto de investigação a produção escrita é empregada e (II) como os autores desses trabalhos compreendem produção escrita. Para isso, as Teses e Dissertações foram analisadas e posteriormente categorizadas por meio da leitura e interpretação das informações referentes ao(s) "Objetivo(s)", "Abordagem Metodológica", "Resultados e Considerações" e aspectos relacionados à "Produção Escrita". 


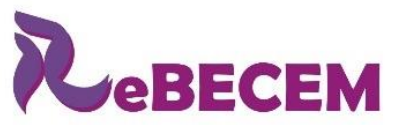

\section{Revista Brasileira de Educação em \\ Ciências e Educação Matemática \\ ISSN 2594-9179}

DOI: https://doi.org/10.33238/ReBECEM.2021.v.5.n.2.27241

Mediante a análise realizada, houve a emergência de três categorias e sete subcategorias que expressam os principais aspectos abordados nas Teses e Dissertações. O Quadro 1 apresenta o resultado do processo de categorização e, na sequência, apresentamos a discussão de cada uma das categorias e subcategorias, além de trechos representativos.

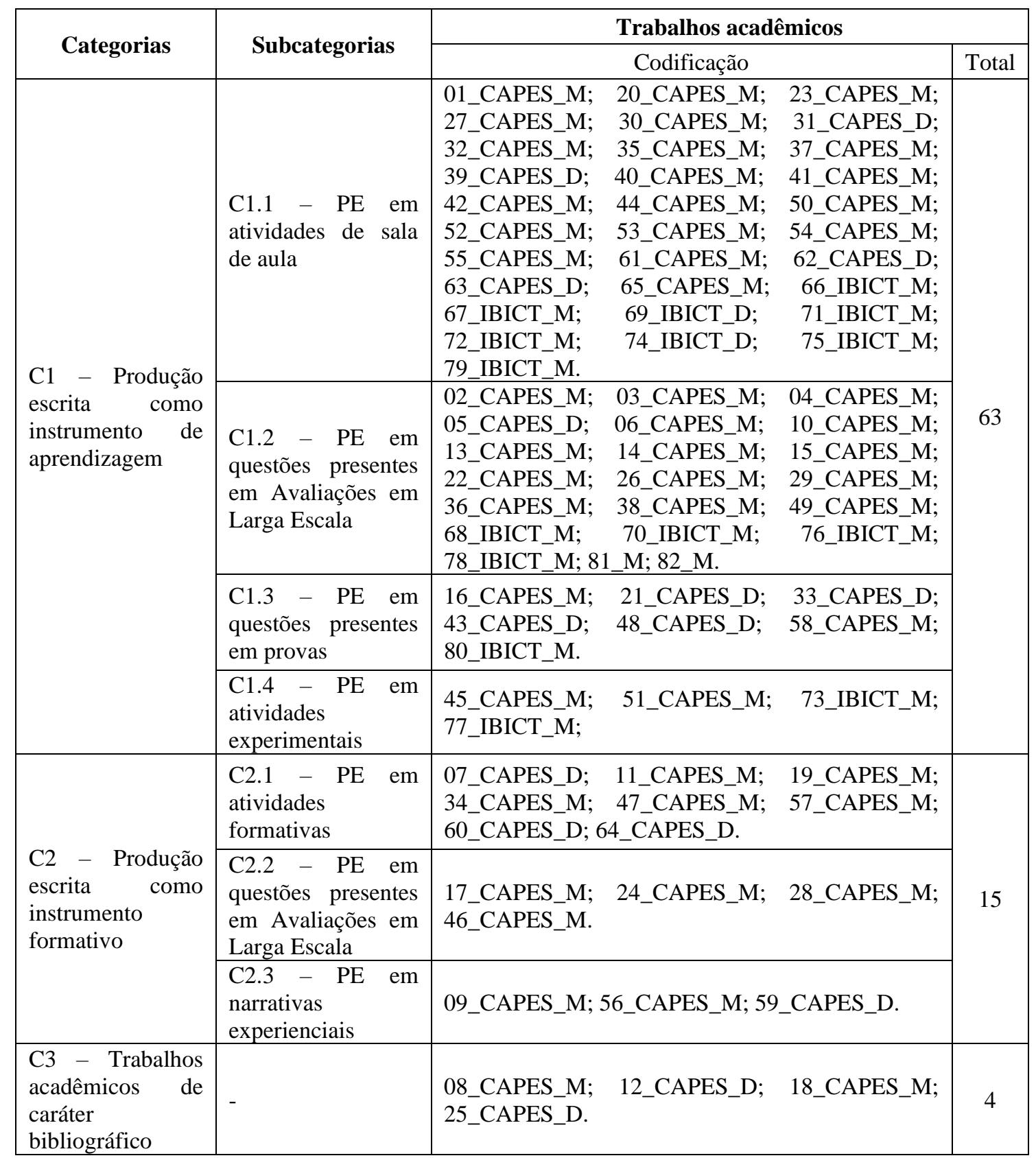

Quadro 1: Categorias e subcategorias relacionadas ao contexto de investigação em que a produção escrita é empregada nos trabalhos acadêmicos selecionados. PE: Produção Escrita.

Fonte: Os autores (2021).

A categoria C1 - Produção escrita como instrumento de aprendizagem compreendeu 63 trabalhos acadêmicos (52 Dissertações e onze Teses) e a emergência de 4 subcategorias. As Teses e Dissertações alocadas nesta categoria apresentam pesquisas 


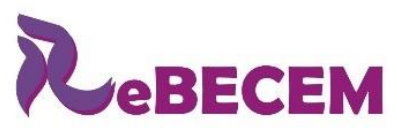

Revista Brasileira de Educação em

Ciências e Educação Matemática

DOI: https://doi.org/10.33238/ReBECEM.2021.v.5.n.2.27241

que utilizaram a produção escrita como instrumento de aprendizagem, ou seja, fizeram uso da PE para conhecer se o sujeito aprendeu ou não determinado conceito, investigando a partir deste instrumento o que foi mobilizado de conhecimento cognitivo e/ou procedimental.

Em geral, ao utilizarem a produção escrita nessas 63 produções acadêmicas, os autores objetivaram: verificar os modos de resolução que os sujeitos utilizam para resolver as questões; compreender como os alunos utilizam as informações do enunciado e, identificar e inventariar os erros mais frequentes; analisar a maneira como os alunos do Ensino Fundamental lidam com tarefas não rotineiras de Matemática em uma Prova em Fases; avaliar as habilidades argumentativas dos alunos fomentadas por uma Sequência Didática de cunho argumentativo; analisar se as atividades experimentais de caráter investigativo contribuíram para a evolução dos conceitos iniciais apresentados pelos estudantes; conhecer que caminhos os alunos escolhem para resolver problemas, que conhecimentos utilizam, quais erros cometem e a natureza deles, e como utilizam as informações contidas nos enunciados das questões; verificar as dificuldades e conversões de ensino-aprendizagem da Função Afim dos alunos do Ensino Médio; analisar se houve compreensão a partir das tipologias discursivas de descrição, narração ou dissertação, produzidas por estudantes; estudar as transformações nas aulas de Ciências cujas metodologias utilizadas pretenderam gerar mudanças na construção de conhecimentos; investigar as contribuições da produção escrita em língua materna para avaliação da aprendizagem.

Enquanto instrumento de aprendizagem, a produção escrita foi utilizada nesses trabalhos para analisar registros dos sujeitos em atividades de sala de aula (subcategoria C1.1), em questões presentes em Avaliações em Larga Escala (subcategoria C1.2), em questões presentes em provas (subcategoria $\mathrm{C} 1.3$ ) e em atividades experimentais (subcategoria C1.4).

Na subcategoria C1.1 - PE em atividades de sala de aula - foram agrupadas 31 produções acadêmicas (25 Dissertações e seis Teses) relacionadas às investigações da produção escrita em atividades realizadas em sala de aula, como apresentado, a seguir:

[27_CAPES_M] PE, de alunos da Educação de Jovens e Adultos $\left(9^{\circ}\right.$ Ano do Ensino Fundamental), em 7 situações-problema de Matemática retiradas da apostila do ENCCEJA.

[39_CAPES_D] PE, de alunos que cursam Ciências Contábeis, em 7 problemas de Matemática adaptados de livros didáticos do Ensino Médio. 
DOI: https://doi.org/10.33238/ReBECEM.2021.v.5.n.2.27241

[42_CAPES_M] PE, de alunos do Ensino Fundamental ( $7^{\circ}$ Ano), em 6 atividades de Ciências, de caráter argumentativo e investigativo, presentes em uma Sequência Didática.

[54_CAPES_M] PE, de alunos do Ensino Médio ( $3^{a}$ Série), em atividades de Biologia que utilizaram Textos de Divulgação Científica.

[67_IBICT_M] PE, de alunos do Ensino Médio ( $3^{\text {a }}$ Série), em uma espécie de carta, chamada de ressonância das aulas de Matemática, endereçada a um colega da classe relatando a dinâmica da aula e o conteúdo abordado na mesma.

Por meio dos exemplos apresentados, percebemos que as atividades de sala de aula contemplam: situações-problema e problemas advindos de apostila e livro didático de Matemática; atividades argumentativas e investigativas e atividades baseadas em Textos de Divulgação Científica, para tratar de conceitos científicos; além de uma espécie de carta, em que o aluno deveria escrever para um colega sobre a dinâmica e o conteúdo abordado na aula de Matemática.

A subcategoria C1.2 - PE em questões presentes em Avaliações em Larga Escala - compreendeu 21 trabalhos acadêmicos (vinte Dissertações e uma Tese) que apresentam investigações da produção escrita em questões de Matemática presentes em avaliações educacionais em larga escala.

As Avaliações em Larga Escala são organizadas e conduzidas por agentes externos à instituição de ensino e não possuem os mesmos objetivos e procedimentos das avaliações realizadas pelos professores em sala de aula. Normalmente organizadas a partir de uma matriz de referência, são desenvolvidas de forma padronizada a muitas pessoas, com o intuito de avaliar o desempenho escolar desses indivíduos, buscando informar o que sabem e são capazes de fazer em um determinado momento e acompanhar sua evolução ao longo dos anos (BLASIS, 2013).

As produções acadêmicas alocadas na subcategoria $\mathrm{C} 1.2$ apresentam investigações da PE em questões de avaliações educacionais em larga escala, tais como o PISA ${ }^{10}$, Prova Brasil ${ }^{11}$, OBMEP $^{12}$, AVA $_{2002}{ }^{13}$, SIMAVE $^{14}$, ENADE $^{15}$ e vestibulares

\footnotetext{
${ }^{10}$ PISA - (Programme for International Student Assessment) Programa Internacional de Avaliação de Estudantes.

${ }^{11}$ Prova Brasil - Avaliação para diagnóstico sobre a qualidade do ensino oferecido pelo sistema educacional brasileiro.

12 OBMEP - Olimpíada Brasileira de Matemática das Escolas Públicas.

${ }^{13}$ AVA/2002 - Avaliação do Rendimento Escolar do Paraná.

${ }^{14}$ SIMAVE - Sistema Mineiro de Avaliação e Equidade da Educação Pública.

15 ENADE - Exame Nacional de Desempenho dos Estudantes, um dos procedimentos de avaliação do Sistema Nacional de Avaliação da Educação Superior.
} 


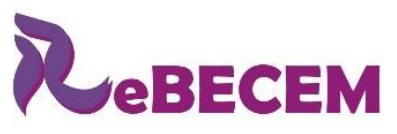

Revista Brasileira de Educação em

Ciências e Educação Matemática

DOI: https://doi.org/10.33238/ReBECEM.2021.v.5.n.2.27241

de universidades públicas do Paraná. Apresentamos, a seguir, alguns excertos destas produções:

[03_CAPES_M] PE, de alunos do Ensino Médio ( $3^{\text {a }}$ Série) e seus professores de Matemática, em 11 questões de Matemática pertencentes à 3 vestibulares de universidades do Paraná (UEL, UEM e UEPG).

[06_CAPES_M] PE, de alunos do Ensino Médio, em 4 questões de Matemática da Matriz de Referência do $9^{\circ}$ Ano da Prova Brasil.

[29_CAPES_M] PE, de professores que ensinam Matemática na Educação Básica, em 8 tarefas presentes em duas questões de Matemática do PISA e da OBMEP.

[36_CAPES_M] PE, de alunos do Ensino Fundamental ( $9^{\circ}$ Ano), em 8 questões de Matemática do banco do SIMAVE.

De acordo com os excertos exemplificados, percebemos que a produção escrita, de alunos e professores, foi investigada em avaliações educacionais em larga escala de caráter internacional (PISA) e nacional (Prova Brasil, OBMEP, SIMAVE e Vestibulares), muitas vezes com questões já validadas pela comunidade educacional, garantindo confiabilidade para a pesquisa.

Na subcategoria C1.3 - PE em questões presentes em provas - foram agrupadas produções acadêmicas (três Dissertações e quatro Teses) compreendendo investigações da produção escrita em questões presentes em situação de provas, como apresentado a seguir:

[43_CAPES_D] PE, de professoras dos anos iniciais do Ensino Fundamental, em 4 questões de Matemática presentes em uma Prova em Fases.

[58_CAPES_M] PE, de alunos que cursam Física (Bacharelado e Licenciatura), em 2 questões presentes em avaliações dissertativas da disciplina Evolução dos Conceitos de Física.

[80_IBICT_M] PE, de alunos que cursam Engenharia Agrícola, em questões de Matemática presentes em duas provas da disciplina Cálculo Diferencial Integral.

Diante dos exemplos, verificamos que a PE foi investigada em questões presentes em provas de dois cursos de nível superior e em uma Prova em Fases. Vale ressaltar que, dentre os 7 trabalhos acadêmicos alocados nesta subcategoria, em 4 deles ocorreu uma investigação da PE em questões presentes em Prova em Fases, um instrumento de avaliação composto por várias fases, em que na primeira os alunos resolvem quais e quantas questões, da prova, julgarem-se capazes de fazer e, nas fases seguintes, têm a oportunidade de resolver as questões não resolvidas anteriormente e/ou refazer, caso seja 


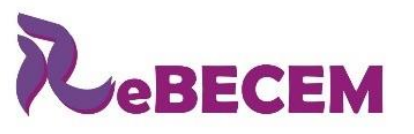

DOI: https://doi.org/10.33238/ReBECEM.2021.v.5.n.2.27241

necessário, as questões já resolvidas (SILVA, 2018).

A subcategoria C1.4 - PE em atividades experimentais - compreendeu 4 Dissertações em que a produção escrita foi investigada por meio de atividades experimentais, como apresentado, a seguir:

[45_CAPES_M] PE, de alunos de um curso técnico de Eletromecânica integrado ao Ensino Médio ( ${ }^{a}$ Série), em 3 atividades de laboratório planejadas na forma de Sequências de Ensino Investigativas durante as aulas de Física.

[73_IBICT_M] PE, de alunos do Ensino Fundamental ( $5^{\circ}$ Ano), em atividades investigativas realizadas na forma de experimentos durante as aulas de Ciências.

As Dissertações alocadas nesta subcategoria pertencem à área das Ciências da Natureza, contemplando duas produções acadêmicas de Ciências (51_CAPES_M e 73_IBICT_M), uma de Física (45_CAPES_M) e uma de Química (77_IBICT_M), em que três apresentaram a análise da $\mathrm{PE}$ em atividades experimentais de caráter investigativo (45_CAPES_M; 51_CAPES_M; 73_IBICT_M). As atividades experimentais podem ser empregadas de diversas maneiras, desde abordagens consideradas tradicionais, como as atividades de demonstração dos fenômenos ocorridos em um experimento e as atividades de verificação de leis e teorias, até aquelas que incitam a criatividade dos alunos, as atividades de investigação. Esta última, possibilita uma maior participação dos estudantes, tornando-os mais ativos no processo de construção do conhecimento, com o auxílio do professor em todas as etapas da investigação, sendo um mediador e facilitador nesse processo de aprendizagem (OLIVEIRA, 2010).

De acordo com os exemplos apresentados, evidenciamos que a produção escrita foi utilizada como instrumento de aprendizagem em 63 trabalhos acadêmicos, buscando conhecer, identificar, verificar, estudar, compreender, analisar aspectos relacionados ao conhecimento mobilizado pelos sujeitos investigados ao resolverem atividades de sala de aula, atividades experimentais e questões presentes em provas e em avaliações educacionais em larga escala.

A categoria C2 - Produção escrita como instrumento formativo - compreendeu 15 produções acadêmicas, dentre elas, onze Dissertações e quatro Teses distribuídas em 3 subcategorias. As pesquisas presentes nesses trabalhos acadêmicos utilizaram a produção escrita como instrumento formativo, uma vez que apresentaram como foco central de investigação a aprendizagem docente, ou seja, os autores dessas produções objetivaram: investigar contribuições para a formação e o desenvolvimento profissional de professores; compreender como o trabalho do professor com determinada estratégia 
DOI: https://doi.org/10.33238/ReBECEM.2021.v.5.n.2.27241

de ensino é reconfigurado; investigar mudanças nas ações docentes de professores; compreender a evolução de licenciandos sobre o processo de ensino-aprendizagem; investigar os movimentos epistêmicos de uma professora; investigar os saberes docentes de licenciados; investigar conhecimentos específicos da docência de professores.

Nessas pesquisas, a produção escrita esteve relacionada às atividades consideradas formativas (subcategoria C2.1), às questões presentes em Avaliações em Larga Escala (subcategoria C2.2) e às narrativas experienciais (subcategoria C2.3).

Na subcategoria C2.1 - PE em atividades formativas - foram alocadas oito produções acadêmicas (cinco Dissertações e três Teses) compreendendo investigações relacionadas às atividades que foram propostas com vistas à formação docente dos sujeitos, a saber por:

[19_CAPES_M] Participantes de um curso de extensão (9 licenciandos e 1 licenciado em Matemática, 1 graduando em Engenharia e 3 Pedagogos) analisaram a PE, de alunos da Educação Básica, em questões de Matemática.

[34_CAPES_M] Uma professora analisou a PE, de alunos que cursam Ciências Biológicas, contendo os resultados das investigações de uma atividade prática.

[47_CAPES_M] PE, de licenciandos que cursam Ciências Biológicas $\left(2^{\circ}\right.$ Ano Licenciatura), em atividades de uma disciplina do curso de graduação.

[64_CAPES_D] PE, de 37 professores de Matemática da Educação Básica, em atividades de Matemática sobre Resolução de Problemas.

Quatro trabalhos acadêmicos alocados nesta subcategoria apresentam pesquisas pautadas em sujeitos que analisaram a PE de outros sujeitos (07_CAPES_D; 19_CAPES_M; 34_CAPES_M e 57_CAPES_M), com foco na aprendizagem docente. Os trabalhos acadêmicos 19_CAPES_M e 34_CAPES_M, por exemplo, possuem pesquisas pautadas em participantes de um curso de extensão e em uma professora que analisaram a produção escrita de alunos da Educação Básica e do Ensino Superior, respectivamente, a fim de: investigar os Saberes Docentes de membros de um curso de extensão (19_CAPES_M); investigar os movimentos epistêmicos de uma professora por meio de sua orientação relacionada à construção de argumentos em produção escrita de alunos do Ensino Superior (34_CAPES_M).

As produções 47_CAPES_M e 64_CAPES_D, ao investigarem a PE em atividades de uma disciplina do curso de Ciências Biológicas e em atividades de Matemática, objetivaram: investigar licenciandos em Ciências Biológicas a fim de compreender a evolução dos mesmos sobre o processo de ensino-aprendizagem, o 
DOI: https://doi.org/10.33238/ReBECEM.2021.v.5.n.2.27241

conhecimento em sala de aula e o papel do professor de Ciências (47_CAPES_M); investigar as possíveis mudanças nas ações docentes de professores que ensinam Matemática, durante e após um curso de Formação Continuada (64_CAPES_D).

A subcategoria C2.2 - PE em questões presentes em Avaliações em Larga Escala - compreendeu quatro Dissertações que apresentam pesquisas relacionadas à formação docente, em que os sujeitos investigados analisaram ou realizaram produção escrita em questões de avaliações educacionais em larga escala, sendo:

[17_CAPES_M] Participantes de um curso de extensão (Professores de Matemática da Educação Básica e Ensino Superior, licenciandos em Matemática e mestrandos em Educação Matemática) analisaram a PE, de alunos da Educação Básica, em questões de Matemática da Prova AVA/2002.

[24_CAPES_M] PE, de 2 professores de Matemática da Educação Básica, em 3 questões de Matemática do PISA.

A pesquisa de 17_CAPES_M objetivou investigar contribuições para a formação profissional do educador ao analisar produções escritas de alunos, ressaltando a utilização desse instrumento como oportunidade de ensino. Enquanto a pesquisa 24_CAPES_M, ao analisar a PE de professores em questões de Matemática do PISA, teve o objetivo de investigar como esses professores lidam com a construção de uma Trajetória Hipotética de Aprendizagem. Da mesma maneira que em 17_CAPES_M, outros dois trabalhos alocados na subcategoria C2.2 também apresentam pesquisas pautadas em sujeitos que analisam a produção escrita de outros sujeitos em questões de Matemática da Prova AVA/2002 (28_CAPES_M e 46_CAPES_M).

$\mathrm{Na}$ subcategoria C2.3 - PE em narrativas experienciais - foram agrupadas 3 produções acadêmicas, dentre elas, duas Dissertações e uma Tese. As produções escritas nesses trabalhos correspondem às narrativas memoriais pessoais e profissionais, narrativas experienciais dentro e fora da sala de aula e registros escritos relacionados às reflexões sobre a prática de professores, respectivamente representadas por:

[09_CAPES_M] PE, de professores que ensinam Matemática nos Anos Iniciais e Finais do Ensino Fundamental, na forma de narrativas memoriais pessoais e profissionais.

[56_CAPES_M] PE, de 4 professoras Educadoras Ambientais (duas da Educação Infantil e duas dos Anos Iniciais do Ensino Fundamental), na forma de narrativas sobre suas experiências dentro e fora da sala de aula.

[59_CAPES_D] PE, de uma professora de Matemática na Educação Básica, na forma de registros escritos nos diários, a respeito de reflexões sobre sua prática e seu 
DOI: https://doi.org/10.33238/ReBECEM.2021.v.5.n.2.27241

pensamento, durante as vivências e experiências com Modelagem Matemática.

As pesquisas dos trabalhos acadêmicos citados objetivaram: investigar as contribuições do processo de realização da produção escrita para a formação de professores (09_CAPES_M); investigar professoras de Educação Ambiental a fim de compreender a constituição do professor Educador Ambiental, conhecer suas concepções de Educação Ambiental e de meio ambiente (56_CAPES_M); investigar o trabalho de uma professora, a fim de compreender como seu trabalho com Modelagem é (re)configurado (59_CAPES_D). Souza (2004) aborda que a narrativa escrita está relacionada às reflexões construídas pelos sujeitos sobre suas experiências e suas aprendizagens estando, portanto, relacionada com o sentido de sua vida e, diante disso, possui o intuito de trabalhar com as possibilidades formativas e com o conhecimento experiencial construído ao longo da vida.

Nas quinze produções acadêmicas agrupadas na categoria $\mathrm{C} 2$, verificamos que a produção escrita foi utilizada como instrumento formativo, uma vez que esteve relacionada com a formação e atividade docente de licenciandos e professores em serviço ao realizarem ou analisarem produções escritas em atividades consideradas formativas, questões presentes em avaliações educacionais em larga escala e em narrativas experienciais.

A categoria C3 - Trabalhos acadêmicos de caráter bibliográfico - abarca duas Dissertações e duas Teses, produções acadêmicas que apresentam pesquisas de caráter bibliográfico, contemplando trabalhos de Doutrado e Mestrado desenvolvidos no âmbito de um grupo de pesquisa em que a produção escrita (de alunos e professores) constituiu o/um instrumento de coleta e análise de dados, a saber pois:

[08_CAPES_M] Investiga os procedimentos metodológicos em trabalhos em que a análise da produção escrita foi utilizada como prática de investigação por meio de 3 teses e 16 dissertações (PE constitui a resolução em questões de Matemática).

[25_CAPES_D] Investiga a utilização da análise da produção escrita em aulas de Matemática por meio de 16 produções acadêmicas realizadas por um grupo de pesquisa relacionadas com o estudo e análise da produção escrita de alunos e/ou professores em questões e aulas de Matemática na perspectiva da Reinvenção Guiada (PE constitui a resolução em questões de Matemática).

Para além da análise apresentada até o momento, mediante às informações dos aspectos relacionados à "Produção Escrita" presentes nos 82 trabalhos acadêmicos, procuramos identificar como os autores dessas produções compreendem produção escrita; em outras palavras, o que vem a ser produção escrita para a área de Ensino de 
DOI: https://doi.org/10.33238/ReBECEM.2021.v.5.n.2.27241

Ciências e Matemática, diante dos trabalhos acadêmicos que versam sobre o tema.

Dentre os 31 trabalhos acadêmicos alocados na subcategoria C1.1 - PE em atividades de sala de aula -, 16 deles contemplam atividades de Matemática em que a produção escrita é considerada o registro ou a resolução em problemas, situaçõesproblema, questões e tarefas envolvendo Equações do $1^{\circ}$ Grau, Progressão Aritmética, Função, Sistemas Lineares, operações com frações em uma Função Afim, representações da Função Afim. Alguns autores explicitam o significado de produção escrita em 6 produções, dentre as 16 citadas, sendo registros escritos, ilustrações e representações geométricas, conforme apresentado, a seguir:

[32_CAPES_M] Desenhos, de alunos de 4 a 5 anos da Educação Infantil, em atividades de produções gráficas que contemplaram áreas do conhecimento, como a geometria.

[35_CAPES_M] Elaboração de histórias e sua transformação em Histórias em Quadrinhos, de alunos do Ensino Fundamental ( $9^{\circ}$ Ano), explorando conceitos matemáticos, envolvendo ilustrações e textos.

[53_CAPES_M] Construção de mosaicos, de alunos do Ensino Fundamental $\left(6^{\circ}\right.$ Ano), em tarefas matemáticas envolvendo registros de representação semiótica.

[55_CAPES_M] Respostas por escrito, de alunos do Ensino Médio ( ${ }^{a}$ Série), em questões de Matemática relacionadas à definição e múltiplas representações do conceito de Função.

Nos trabalhos acadêmicos relacionados à área Ciências da Natureza, pertencentes à subcategoria $\mathrm{C} 1.1$, a produção escrita é compreendida como registros escritos (seis de Física; seis de Ciências; um de Biologia; um de Química) e registros escritos, desenhos e colagens ( 1 de Ciências), em atividades realizadas em sala de aula, de acordo com os exemplos apresentados, a seguir:

[61_CAPES_M] Desenhos, colagens em cartaz e História em Quadrinhos, de alunos do Ensino Fundamental ( $4^{\circ}$ ano), em atividades de Ciências utilizando diversas Estratégias Didáticas.

[63_CAPES_D] Perguntas e perguntas com respostas, de alunos que cursam Química (Licenciatura), sobre textos estudados em atividades envolvendo estratégias de leitura.

[71_IBICT_M] Redações, de alunos do Ensino Médio, baseadas em artigos de Divulgação Científica em atividades de Biologia.

[74_IBICT_D] Registros escritos, de alunos do Ensino Médio ( $3^{\text {a }}$ Série), sobre dois Casos estudados na disciplina de Física.

De acordo com os 25 trabalhos acadêmicos alocados nas subcategorias C1.2 e 


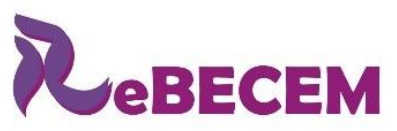

Revista Brasileira de Educação em

Ciências e Educação Matemática

DOI: https://doi.org/10.33238/ReBECEM.2021.v.5.n.2.27241

C2.2, que contemplam investigações com questões de Matemática presentes em avaliações educacionais em larga escala, em 24 deles a produção escrita consiste na resolução das questões, consideradas: discursivas e não rotineiras, ou apenas não rotineiras (questões pertencentes ao PISA); abertas e discursivas, ou apenas abertas (questões referentes à Prova AVA/2002); e discursivas (questões do ENADE). Nas questões de Matemática do SIMAVE (presentes em uma produção acadêmica), a produção escrita esteve relacionada ao registro das explicações das respostas dos alunos, uma vez que se tratavam de questões de múltipla escolha. Seguem dois exemplos:

[14_CAPES_M] Resolução, de alunos da Educação Básica na faixa etária estabelecida pelo PISA ( 15 anos e 3 meses a 16 anos e 2 meses), em questões de Matemática do PISA consideradas discursivas e não rotineiras.

[28_CAPES_M] Resolução, de alunos da Educação Básica, em questões abertas discursivas de Matemática da Prova AVA/2002.

Para Silva (2005), as questões abertas são também chamadas de discursivas e requerem que o indivíduo mostre os caminhos que foram seguidos para encontrar uma resposta. Diferente das questões consideradas fechadas, objetivas ou de múltipla escolha, as questões abertas não apresentam, associadas ao seu enunciado, alternativas de resposta. Em alguns trabalhos acadêmicos, as questões presentes na prova do PISA foram consideradas, além de discursivas, não rotineiras. Buriasco (1999) define como questões não rotineiras aquelas que muito pouco ou quase nunca aparecem na sala de aula ou no material de apoio (livro didático e/ou apostilas).

Algumas das questões de avaliações educacionais em larga escala presentes nos 25 trabalhos acadêmicos solicitaram a resolução de problemas e expressões numéricas, envolvendo cálculos de operações com números racionais, cálculo de área de figuras planas, equação de $2^{\circ}$ grau, noção de volume, conceitos algébricos.

Nos trabalhos acadêmicos que apresentam questões presentes em situação de provas (subcategoria $\mathrm{C} 1.3$ ) a produção escrita está relacionada à resolução das questões de Matemática (seis trabalhos acadêmicos) - algumas consideradas abertas (dois trabalhos acadêmicos) ou não rotineiras (um trabalho acadêmico) -, e à resposta, de forma dissertativa, das questões de Física presentes em uma prova, de acordo com os exemplos:

[16_CAPES_M] Resolução, de alunos do Ensino Fundamental ( $5^{\circ}$ Ano), em questões de Matemática, consideradas não rotineiras, presentes em uma Prova em Fases. 
[33_CAPES_D] Resolução, de alunos que cursam o Técnico de Nível Médio Integrado em Vestuário ( $2^{\circ}$ Ano), em questões abertas de Matemática de uma Prova em Fases.

[58_CAPES_M] Respostas, de alunos que cursam Física (Bacharelado e Licenciatura), em questões dissertativas presentes em provas de um módulo de ensino sobre Arte e História e Filosofia da Ciência.

As produções escritas presentes em atividades experimentais, referentes aos trabalhos acadêmicos agrupados na subcategoria $\mathrm{C} 1.4$, são consideradas registros na forma de desenhos e escrita (trabalhos acadêmicos contemplando atividades de Física e de Ciências, um de cada) e registros/respostas de forma escrita (trabalhos acadêmicos contemplando atividades de Ciências e de Química, um de cada), a saber por:

[51_CAPES_M] Registros, de alunos do Ensino Fundamental ( $2^{\circ}$ Ano), na forma escrita ou em desenhos, dos fenômenos observados nas atividades experimentais de Ciências presentes em uma Sequência de Ensino Investigativa.

[77_IBICT_M] Respostas discursivas, de alunos que cursam o Técnico em Química ( $2^{\circ}$ Ano), em atividades de Química, relacionadas à verificação do grau verde ${ }^{16}$ (greenness) de um experimento.

Em relação aos trabalhos acadêmicos que apresentam atividades consideradas formativas (subcategoria C2.1), a produção escrita consiste na resolução de atividades de Matemática (três trabalhos acadêmicos) e em registros escritos (dois trabalhos de Matemática; dois trabalhos de Biologia; um trabalho de Física), como os exemplos apresentados, a seguir:

[11_CAPES_M] Textos, de membros de um Grupo de Trabalho da área da Matemática, sobre o processo de elaboração de Propostas de Trabalho envolvendo as práticas profissionais e práticas implementadas em sala de aula.

[57_CAPES_M] Resolução, de alunos da Educação Básica, em questões abertas de Matemática.

[60_CAPES_D] Questões elaboradas, por alunos que cursam Física (Licenciatura), sobre os assuntos trados em Documentários de Divulgação Científica.

Como visto anteriormente, na subcategoria C2.3 foram agrupados 3 trabalhos acadêmicos em que as produções escritas correspondem às narrativas experienciais dos professores de Matemática e de Ciências investigados. Nesse sentido, a produção escrita

${ }^{16} \mathrm{O}$ grau verde de um experimento baseia-se nos princípios da Química Verde, que tem como principal objetivo minimizar ou erradicar o uso de substâncias nocivas. Assim, por meio de métodos utilizados nas aulas experimentais, pode-se avaliar as práticas inerentes à atividade química por meio de situações em que os princípios do Grau Verde foram ou não atendidos (MELO, 2019). 
trata-se de registros escritos.

A categoria C3 agrupou quatro trabalhos acadêmicos de caráter bibliográfico. A produção escrita presente nas Teses e Dissertações inventariadas por esses trabalhos se relaciona às resoluções em questões de Matemática, constituindo o/um instrumento de coleta e análise de dados.

Diante do apresentado, no que diz respeito à compreensão de produção escrita para a área de Ensino de Ciências e Matemática, considerando as 82 produções acadêmicas que versam sobre o tema, verificamos que os autores consideram como PE as resoluções matemáticas, as respostas escritas ou registros escritos, os desenhos/ilustrações, as colagens e as representações geométricas nas inúmeras atividades realizadas pelos sujeitos investigados.

A área de Matemática compreendeu a maior quantidade de trabalhos acadêmicos selecionados neste estudo (58 trabalhos) e a produção escrita, em 47 deles, esteve relacionada às resoluções das questões de Matemática (algumas consideradas discursivas, e/ou abertas, e/ou não rotineiras) presentes em avaliações educacionais em larga escala, provas, atividades de sala de aula e atividades formativas. As produções escritas em Matemática que compreenderam registros escritos, desenhos/ilustrações e representações geométricas constituíram: explicação da resposta em questões de uma avaliação em larga escala; definição de alguns conceitos matemáticos e produções textuais em atividades de escrita e elaboração de histórias para compor uma História em Quadrinhos; textos sobre o processo de elaboração de Propostas de Trabalho e nas narrativas experienciais de professores; desenhos em atividades de produções gráficas; ilustrações de Histórias em Quadrinhos explorando conceitos matemáticos; construção de mosaicos em tarefas envolvendo registros de representação semiótica.

Em 21 trabalhos acadêmicos relacionados às Ciências da Natureza, a produção escrita foi considerada apenas registros escritos, enquanto que, em outros 3 trabalhos pertencentes à área, a PE constituiu registros escritos, desenhos e colagens, compreendendo: respostas em questões dissertativas presentes em provas e em atividades de sala de aula; formulação de questões e respostas em atividades de sala de aula; textos e resumos a partir de atividades de sala de aula e de atividades experimentais; desenhos, colagens e a elaboração de Histórias em Quadrinhos em atividades explorando diversas Estratégias Didáticas; registros por escrito e/ou em desenhos dos fenômenos observados em atividades experimentais; textos constituindo narrativas experienciais de professores.

Diante dessas produções acadêmicas, percebemos que as atividades de escrita 


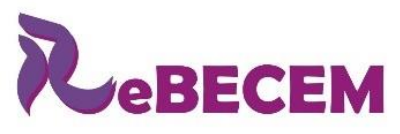

Revista Brasileira de Educação em

Ciências e Educação Matemática

DOI: https://doi.org/10.33238/ReBECEM.2021.v.5.n.2.27241

estiveram, em sua maioria, relacionadas com os alunos e/ou professores pertencentes aos Anos Finais do Ensino Fundamental, ao Ensino Médio, aos cursos de Nível Técnico e de Ensino Superior. Enquanto que as produções escritas na forma de desenhos/ilustrações, colagens e representações geométricas se associaram aos registros de alunos da Educação Infantil e dos Anos Iniciais do Ensino Fundamental, como por exemplo: construção de mosaicos em atividades de Matemática realizada por alunos do $6^{\circ}$ Ano; registro na forma de desenhos nas atividades experimentais realizados por alunos do $2^{\circ}$ Ano; desenhos, colagens em cartaz e elaboração de Histórias em Quadrinhos em atividades explorando diversas Estratégias Didáticas realizadas por alunos do $4^{\circ}$ Ano; desenhos em atividades de produções gráficas envolvendo geometria realizados por alunos da Educação Infantil.

Compartilhando das ideias do filósofo e psicólogo Maurice Merleau-Ponty e da médica e educadora Maria Montessori, o desenho infantil demonstra a relação que a criança tem com o outro, com o mundo visível e com a realidade percebida, exprimindo afetividade, imaginação, conhecimento e fidedignidade, tratando-se de uma escrita feita de imagens (ANDRADE, 2005). Pillar (1996, p. 201) ressalta que o desenho constitui "uma atividade que envolve a inteligência, o pensamento, a cognição", implicando na construção de conhecimentos, especialmente os relacionados à escrita. Nesse sentido, nos primeiros anos escolares o desenho e a escrita dividem espaço e, à medida que ocorre o desenvolvimento da criança, há uma evolução comum às duas atividades, em que a escrita acaba representando o nome dos objetos expressados por desenhos (PILLAR, 1996).

$\mathrm{Na}$ próxima seção, apresentamos algumas considerações a respeito das intencionalidades desta pesquisa, provenientes da análise das 82 produções acadêmicas que investigaram aspectos relacionados à produção escrita.

\section{Considerações finais a respeito das produções analisadas}

Neste artigo, apresentamos uma pesquisa de caráter bibliográfico que buscou conhecer as investigações atinentes à produção escrita na área de Ensino de Ciências e Matemática a partir de um mapeamento de produções científicas presentes em dois bancos de Teses e Dissertações nacionais: CAPES e IBICT.

Selecionamos para o estudo 65 Dissertações e 17 Teses, totalizando 82 trabalhos acadêmicos publicados no período de 2005-2019 em 27 instituições nacionais de Ensino Superior, constituindo pesquisas desenvolvidas na Educação Infantil, nos Ensinos 
DOI: https://doi.org/10.33238/ReBECEM.2021.v.5.n.2.27241

Fundamental, Médio e Superior, e em cursos de nível técnico, envolvendo as áreas de Biologia, Ciências, Física, Matemática e Química, com maior contribuição da Matemática, abarcando 70,7\% das produções.

Diante das informações coletadas, que se referem ao(s) "Objetivo(s)", "Abordagem Metodológica", "Resultados e Considerações" e aspectos relacionados à "Produção Escrita", os trabalhos acadêmicos selecionados foram analisados com o intuito de identificarmos em que contexto de investigação a produção escrita foi empregada e como os autores desses trabalhos compreendem o termo produção escrita.

Mediante a análise para identificar em que contexto de investigação a produção escrita foi empregada, houve a emergência de categorias e subcategorias em que foi possível evidenciar que as Teses e Dissertações na área de Ensino de Ciências e Matemática apresentam investigações em que a produção escrita foi utilizada como instrumento de aprendizagem (em 63 produções acadêmicas) ou como instrumento formativo (em quinze produções acadêmicas), além de quatro pesquisas de caráter bibliográfico.

Os trabalhos acadêmicos que utilizaram a produção escrita como instrumento de aprendizagem objetivaram conhecer, identificar, verificar, estudar, compreender, e/ou analisar aspectos relacionados ao conhecimento mobilizado pelos sujeitos investigados ao resolverem atividades de sala de aula, atividades experimentais e questões presentes em provas e em avaliações educacionais em larga escala.

Já os trabalhos acadêmicos que utilizaram a produção escrita como instrumento formativo compreenderam investigações relacionadas à atividade e à aprendizagem docente de licenciandos e professores em serviço ao realizarem ou analisarem produções escritas em atividades formativas, questões presentes em avaliações educacionais em larga escala e em narrativas experienciais.

No que tange a compreensão de produção escrita para a área de Ensino de Ciências e Matemática verificamos que, em geral, os autores consideram como PE resoluções matemáticas, respostas escritas ou registros escritos, desenhos/ilustrações, colagens e representações geométricas nas inúmeras atividades realizadas pelos alunos e professores investigados nesses trabalhos. Em 47 trabalhos acadêmicos, a produção escrita esteve relacionada com as resoluções das questões de Matemática, algumas consideradas discursivas, e/ou abertas, e/ou não rotineiras. Onze produções acadêmicas da Matemática e 3 das Ciências da Natureza consideraram como produção escrita registros escritos, e/ou desenhos/ilustrações, e/ou representações geométricas, e/ou 


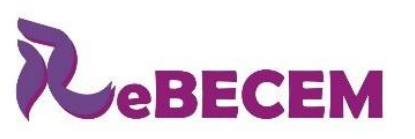

Revista Brasileira de Educação em

Ciências e Educação Matemática

DOI: https://doi.org/10.33238/ReBECEM.2021.v.5.n.2.27241

colagens; enquanto apenas registros escritos foram sinônimos de produção escrita em

21 trabalhos acadêmicos relacionados às Ciências da Natureza.

Diante da presente investigação, constatamos que, para a área de Ensino de Ciências e Matemática, a produção escrita não se restringe à escrita de textos, uma vez que se apresenta também na forma de desenhos, representações geométricas, colagens e resoluções matemáticas.

Nesse sentido, no contexto em que está inserido este levantamento bibliográfico considerando os 82 trabalhos acadêmicos selecionados, a BNCC e os referenciais relacionados às múltiplas representações, inferimos que produção escrita pode ser entendida, na área de Ensino de Ciências e Matemática, como toda representação escrita, constituída de textos em linguagem natural ${ }^{17}$, desenhos e imagens, esquemas, gráficos, tabelas, registros algébricos e geométricos, realizada por sujeitos ao explicitarem ideias e entendimentos em diversas situações científicas e/ou matemáticas que exijam a realização de produção escrita.

Salientamos que, assim como para a área da Matemática, a atividade e a análise da produção escrita nas aulas das Ciências da Natureza podem possibilitar aprendizagens para os alunos e reflexões para o professor, contribuindo para os processos de ensino e de aprendizagem com vistas ao Letramento Científico necessário a todo cidadão.

\section{Referências}

ALVES, R. M. F. Uma análise da produção escrita de alunos do Ensino Médio em questões abertas de Matemática. 2006. 158 f. Dissertação (Mestrado em Ensino de Ciências e Educação Matemática) - Universidade Estadual de Londrina, Londrina, 2006.

ANDRADE, L. C. O desenho como expressão no aprendizado infantil: caminhos e possibilidades. 2005. 126 f. Dissertação (Mestrado em Educação) - Universidade Federal de Mato Grosso do Sul, Campo Grande, 2005.

BARDIN, L. Análise de Conteúdo. São Paulo: Edições 70, 2016.

\footnotetext{
$17 \mathrm{Na}$ presente investigação, a linguagem natural, citada nos referencias relacionados às múltiplas representações e entendida como linguagem materna pela BNCC, refere-se à linguagem que o sujeito possui e mobiliza ao realizar a produção escrita. Por exemplo, a leitura de algum conteúdo matemático necessita, ao mesmo tempo, que o sujeito mobilize a linguagem natural (Língua Portuguesa) e a linguagem matemática (BASTOS, 2016). Um segundo exemplo, relacionado à passagem da linguagem natural para a linguagem algébrica, indica que essa conversão ocorre quando o enunciado de determinada atividade matemática é dado em linguagem natural, sendo necessário escrevê-lo em uma expressão na forma algébrica para resolver a atividade (JACOMELLI, 2006).
} 
BARRERA, S. D.; SANTOS, M. J. Produção escrita de narrativas: influência de condições de solicitação. Educar em Revista, Curitiba, n. 62, p. 69-85, 2016.

BASTOS, C. L. de. Representações em Matemática: Observações para o Ensino e a Aprendizagem em Geometria. 2016. 77 f. Dissertação (Mestrado Profissional em Matemática em Rede Nacional) - Instituto de Matemática e Estatística, Universidade Federal de Goiás, Goiânia, 2016.

BLASIS, E. Avaliações em Larga Escala: contribuições para a melhoria da qualidade na educação. Cadernos Cenpec, São Paulo, v. 3, n. 1, p. 251-268, 2013.

BONI, K. T.; LABURÚ, C. E.; CAMARGO FILHO, P. S. A teoria dos campos conceituais e a diversidade representacional: Leituras convergentes para a Educação Matemática e Científica. Vidya, Santa Maria, v. 38, n. 1, p. 75-90, 2018.

BRASIL. Ministério da Educação. Base Nacional Comum Curricular. Brasília, 2018.

BURIASCO, R. L. C. Avaliação em Matemática: um estudo das respostas de alunos e professores. 1999. 238 f. Tese (Doutorado em Educação) - Universidade Estadual Paulista Júlio de Mesquita Filho, Marília, 1999.

CELESTE, L. B. A produção escrita de alunos do Ensino Fundamental em questões de Matemática do PISA. 2008. 96 f. Dissertação (Mestrado em Ensino de Ciências e Educação Matemática) - Universidade Estadual de Londrina, Londrina, 2008.

DUVAL, R. Semiosis y pensamiento humano: registros semióticos y aprendizajes intelectuales. Santiago de Cali: Peter Lang, 2004.

FERREIRA, N. S. de A. As pesquisas denominadas "Estado da Arte". Educação e Sociedade, Campinas, v. 23, n. 79, p. 257-272, 2002.

GIL, A. C. Como elaborar Projetos de Pesquisa. 6. ed. São Paulo: Atlas, 2017.

HENRIQUES, A.; PONTE, J. P. da. As Representações como suporte do raciocínio Matemático dos alunos quando exploram Atividades de Investigação. Bolema, Rio Claro, v. 28, n. 48, p. 276-298, 2014.

JACOMELLI, K. Z. A linguagem natural e a linguagem algébrica: nos livros didáticos e em uma classe de $7^{\text {a }}$ série do Ensino Fundamental. 2006. 175 f. Dissertação (Mestrado em Educação Científica e Tecnológica) - Universidade Federal de Santa Catarina, Florianópolis, 2006. 
DOI: https://doi.org/10.33238/ReBECEM.2021.v.5.n.2.27241

KLEIN, T. A. da S.; LABURÚ, C. E. Multimodos de representação e teoria da aprendizagem significativa: possíveis interconexões na construção do conceito de biotecnologia. Revista Ensaio, Rio de Janeiro, v. 14, n. 2, p. 137-152, 2012.

LABURÚ, C. E.; BARROS, M. A.; SILVA, O. H. M. da. Multimodos e múltiplas representações, aprendizagem significativa e subjetividade: três referenciais conciliáveis da Educação Científica. Ciência e Educação, Bauru, v. 17, n. 2, p. 469-487, 2011.

LABURÚ, C. E.; FARIA, R. A. de. Coordenação e multiplicidade representacional em uma atividade de Função do $1^{\circ}$ Grau. Revista Paranaense de Educação Matemática, Campo Mourão, v. 7, n. 13, p. 61-86, 2018.

LIMA, V. W.; FERRETTI-SOARES, V. A. de S.; SILVEIRA, E. L. A produção escrita no Ensino Fundamental: o quê, como e para quem se escreve? Confluência, Rio de Janeiro, n. 47, p. 261-284, 2015.

LOPEZ, J. M. S. Análise interpretativa de questões não-rotineiras de Matemática. 2010. 141 f. Dissertação (Mestrado em Ensino de Ciências e Educação Matemática) - Universidade Estadual de Londrina, Londrina, 2010.

MELO, N. R. V. de. Experimentos verdes em Química Orgânica: uma proposta de aplicação do método da Estrela Verde para o curso Técnico em Química. 2019. 108 f. Dissertação (Mestrado Profissional em Educação e Docência) - Universidade Federal de Minas Gerais, Belo Horizonte, 2019.

NOGARO, A.; PORTO, A. P. T.; PORTO, L. T. A produção escrita e a formação de professores. Revista Educação (UFSM), Santa Maria, v. 44, p. 1-25, 2019.

OLIVEIRA, J. R. S. de. Contribuições e abordagens das atividades experimentais no Ensino de Ciências: reunindo elementos para a prática docente. Acta Scientiae, Canoas, v. 12, n. 1, p. 139-153, 2010.

PEDROCHI JUNIOR, O. Avaliação como oportunidade de aprendizagem em Matemática. 2012. 56 f. Dissertação (Mestrado em Ensino de Ciências e Educação Matemática) Universidade Estadual de Londrina, Londrina, 2012.

PEREIRA, F. F.; DALTO, J. O. Tarefas de Análise da Produção Escrita: uma proposta de curso de extensão. Londrina/Cornélio Procópio: Universidade Tecnológica Federal do Paraná, 2019. (Produto Educacional).

PILLAR, A. D. Desenho e escrita como sistemas de representação. Porto Alegre: Artes Médicas, 1996. 
DOI: https://doi.org/10.33238/ReBECEM.2021.v.5.n.2.27241

RIBAS, J. F.; BROIETTI, F. C. D. Um estudo da produção escrita de estudantes do Ensino Médio em questões de Ciências do PISA. Amazônia - Revista de Educação em Ciências e Matemática, Belém, v. 16, n. 36, p. 244-262, 2020.

SANTOS, E. R. dos. Análise da produção escrita em Matemática: de estratégia de avaliação a estratégia de ensino. 2014. 157 f. Tese (Doutorado em Ensino de Ciências e Educação Matemática) - Universidade Estadual de Londrina, Londrina, 2014.

SILVA, G. dos S. e. Um olhar para os processos de aprendizagem e de ensino por meio de uma Trajetória de Avaliação. 2018. 166 f. Tese (Doutorado em Ensino de Ciências e Educação Matemática) - Universidade Estadual de Londrina, Londrina, 2018.

SILVA, M. C. N. Do observável para o oculto: Um estudo da produção escrita de alunos da $4^{\mathrm{a}}$. Série em questões de Matemática. 2005. 130 f. Dissertação (Mestrado em Ensino de Ciências e Educação Matemática) - Universidade Estadual de Londrina, Londrina, 2005.

SOUZA, E. C. O conhecimento de si: narrativas do itinerário escolar e formação de professores. 2004. 344 f. Tese (Doutorado em Educação) - Faculdade de Educação, Universidade Federal da Bahia, Salvador, 2004.

STANZANI, E. de L. Saberes Docentes e a prática nos estágios: possibilidades na formação do futuro professor de Química. 2018. 251 f. Tese (Doutorado em Educação para a Ciência) Universidade Estadual Paulista Júlio de Mesquita Filho, Bauru, 2018.

WARTHA, E. J.; REZENDE, D. de B. As representações no ensino de química na perspectiva da semiótica peirceana. Educação Química en Punto de Vista, Foz do Iguaçu, v. 1, n. 1, p. 181-202, 2017.

Recebido em: 19 de abril de 2021

Aceito em: 26 de julho de 2021 
Apêndice 1: Lista das referências das teses e dissertações constituintes do corpus e suas respectivas codificações.

\begin{tabular}{|c|c|}
\hline Referência & Codificação \\
\hline $\begin{array}{l}\text { MARQUES, M. C. de A. Avaliação como processo de comunicação e regulação } \\
\text { da aprendizagem de equações do } \mathbf{1}^{\circ} \text { grau: contribuições da produção escrita. } 2012 . \\
233 \text { f. Dissertação (Mestrado Profissional em Ensino de Ciências e Matemática) - } \\
\text { Universidade Estadual da Paraíba, Campina Grande, } 2012 \text {. }\end{array}$ & 01_CAPES_M \\
\hline $\begin{array}{l}\text { CELESTE, L. B. A produção escrita de alunos do Ensino Fundamental em } \\
\text { questões de Matemática do PISA. 2008. } 85 \text { f. Dissertação (Mestrado em Ensino de } \\
\text { Ciências e Educação Matemática) - Universidade Estadual de Londrina, Londrina, } \\
2008 \text {. }\end{array}$ & 02_CAPES_M \\
\hline $\begin{array}{l}\text { SANTOS, G. L. dos. Como professores e alunos do Ensino Médio lidam com } \\
\text { conteúdos algébricos em sua Produção Escrita. 2010. } 136 \text { f. Dissertação } \\
\text { (Mestrado em Ensino de Ciências e Educação Matemática) - Universidade Estadual } \\
\text { de Londrina, Londrina, 2010. }\end{array}$ & 03_CAPES_M \\
\hline $\begin{array}{l}\text { DALTO, J. O. A produção escrita em Matemática: análise interpretativa da } \\
\text { questão discursiva de Matemática comum à } 8^{\text {a }} \text { série do Ensino Fundamental e à } 3^{\text {a }} \\
\text { série do Ensino Médio da AVA/2002. 2007. } 100 \text { f. Dissertação (Mestrado em Ensino } \\
\text { de Ciências e Educação Matemática) - Universidade Estadual de Londrina, } \\
\text { Londrina, 2007. }\end{array}$ & 04_CAPES_M \\
\hline $\begin{array}{l}\text { CIANI, A. B. O realístico em questões não-rotineiras de Matemática. 2012. } 166 \\
\text { f. Tese (Doutorado em Ensino de Ciências e Educação Matemática) - Universidade } \\
\text { Estadual de Londrina, Londrina, } 2012 .\end{array}$ & 05_CAPES_D \\
\hline $\begin{array}{l}\text { ZAGNOLI, T. de P. Uma análise do erro de um grupo de estudantes do Ensino } \\
\text { Médio em uma escola de Juiz de Fora - MG sob a ótica Sociocontextual. } 2017 . \\
134 \text { f. Dissertação (Mestrado Profissional em Educação Matemática) - Universidade } \\
\text { Federal de Juiz de Fora, Juiz de Fora, } 2017 .\end{array}$ & 06_CAPES_M \\
\hline $\begin{array}{l}\text { SCHNEIDER, M. R. Produção escrita em aulas de Matemática: elo entre o } \\
\text { desenvolvimento profissional e a qualidade do processo motivacional de quem } \\
\text { ensina Matemática. 2016. } 527 \text { f. Tese (Doutorado em Educação Científica e } \\
\text { Tecnológica) - Universidade Federal de Santa Catarina, Florianópolis, } 2016 \text {. }\end{array}$ & 07_CAPES_D \\
\hline $\begin{array}{l}\text { BARRETTO, A. C. Procedimentos da análise da produção escrita em } \\
\text { Matemática no contexto do GEPEMA: um olhar para dentro. 2018. } 116 \mathrm{f} \text {. } \\
\text { Dissertação (Mestrado em Ensinode Ciênciase Educação Matemática) - } \\
\text { Universidade Estadualde Londrina, Londrina, 2018. }\end{array}$ & 08_CAPES_M \\
\hline $\begin{array}{l}\text { BARROS, M. A. T. de. Processo de produção escrita de professores que ensinam } \\
\text { Matemática em Grupos de Pesquisa. 2016. } 108 \text { f. Dissertação (Mestrado em } \\
\text { Educação Matemática) - Pontifícia Universidade Católica de São Paulo, São Paulo, } \\
2016 .\end{array}$ & 09_CAPES_M \\
\hline $\begin{array}{l}\text { ALMEIDA, V. L. C. de. Questões não-rotineiras: a produção escrita de alunos da } \\
\text { graduação em Matemática. 2009. } 144 \text { f. Dissertação (Mestrado em Ensino de } \\
\text { Ciências e Educação Matemática) - Universidade Estadual de Londrina, Londrina, } \\
2009 .\end{array}$ & 10_CAPES_M \\
\hline $\begin{array}{l}\text { OVANDO, E. C. B. Sobre um processo de elaboração de Propostas de Trabalho } \\
\text { de Matemática para o Ensino Fundamental. } 2017.112 \text { f. Dissertação (Mestrado } \\
\text { em Educação Matemática) - Universidade Federal de Mato Grosso do Sul, Campo } \\
\text { Grande, } 2017 .\end{array}$ & 11_CAPES_M \\
\hline $\begin{array}{l}\text { PASSOS, A. Q. Van Hiele, Educação Matemática Realística e GEPEMA: } \\
\text { algumas aproximações. 2015. } 147 \text { f. Tese (Doutorado em Ensino de Ciências e } \\
\text { Educação Matemática) - Universidade Estadual de Londrina, Londrina, } 2015 .\end{array}$ & 12_CAPES_D \\
\hline $\begin{array}{l}\text { SANTOS, E. R. dos. Estudo da produção escrita de estudantes do Ensino Médio } \\
\text { em questões discursivas não rotineiras de Matemática. 2008. } 166 \text { f. Dissertação } \\
\text { (Mestrado em Ensino de Ciências e Educação Matemática) - Universidade Estadual } \\
\text { de Londrina, Londrina, 2008. }\end{array}$ & 13_CAPES_M \\
\hline
\end{tabular}

Continua. 
Continuação.

LOPEZ, J. M. S. Análise interpretativa de questões não-rotineiras de Matemática. 2010. 141 f. Dissertação (Mestrado em Ensino de Ciências e Educação Matemática) - Universidade Estadual de Londrina, 2010.

BEZERRA, G. C. Registros escritos de alunos em questões não-rotineiras da área de conteúdo quantidade: um estudo. 2010. 183 f. Dissertação (Programa de Pós-Graduação em Ensino de Ciências e Educação Matemática) - Universidade Estadual de Londrina, Londrina, 2010.

PRESTES, D. B. Prova em Fases de Matemática: uma experiência no $5^{\circ}$ Ano do Ensino Fundamental. 2015. 122 f. Dissertação (Mestrado em Ensino de Ciências e Educação Matemática) - Universidade Estadual de Londrina, Londrina, 2015.

BRITTO, M. L. B. Uma discussão de discussões de professores que ensinam Matemática em um Grupo de Trabalho. 2015. 154 f. Dissertação (Mestrado em Educação Matemática) - Universidade Federal de Mato Grosso do Sul, Campo Grande, 2015.

PEDROCHI JUNIOR, O. Avaliação como oportunidade de aprendizagem em Matemática. 2012. 56 f. Dissertação (Mestrado em Ensino de Ciências e Educação Matemática) - Universidade Estadual de Londrina, Londrina, 2012.

SILVA, D. Q. da. Processo de produção de saberes docentes sobre temáticas da avaliação e análise da produção escrita em Matemática em um curso de extensão. 2017. 137 f. Dissertação (Mestrado Profissional em Ensino de Matemática) - Universidade Tecnológica Federal do Paraná, Londrina, 2017.

CARDOSO, M. A. M. Análise da produção escrita em Matemática: quatro histórias da construção de uma proposta de ensino para a Educação de Jovens e Adultos. 2017. 101 f. Dissertação (Mestrado Profissional em Ensino de Matemática)

- Universidade Tecnológica Federal do Paraná, Londrina, 2017.

SILVA, G. dos S. e. Um olhar para os processos de aprendizagem e de ensino por meio de uma trajetória de avaliação. 2018. 166 f. Tese (Doutorado em Ensino de Ciências e Educação Matemática) - Universidade Estadual de Londrina, Londrina, 2018.

SANTOS, J. R. V. dos. O que alunos da Escola Básica mostram saber por meio de sua produção escrita em Matemática. 2007. 114 f. Dissertação (Mestrado em Ensino de Ciências e Educação Matemática) - Universidade Estadual de Londrina, Londrina, 2007.

MACHADO, D. S. Produção escrita: contribuições para a construção de conhecimentos nas aulas de Ciências no Ensino Fundamental. 2007. 101 f. Dissertação (Mestrado em Educação em Ciências e Matemática) - Pontifícia Universidade Católica do Rio Grande do Sul, Porto Alegra, 2007.

ROSSETTO, H. H. P. Trajetória Hipotética de Aprendizagem sob um olhar realístico. 2016. 104 f. Dissertação (Mestrado em Ensino de Ciências e Educação Matemática) - Universidade Estadual de Londrina, Londrina, 2016.

16_CAPES_M

17_CAPES_M

18_CAPES_M

19_CAPES_M

SANTOS, E. R. dos. Análise da produção escrita em Matemática: de estratégia de avaliação a estratégia de ensino. 2014. 157 f. Tese (Doutorado em Ensino de Ciências e Educação Matemática) - Universidade Estadual de Londrina, Londrina, 2014.

FERREIRA, P. E. A. Análise da produção escrita de professores da Educação Básica em questões não-rotineiras de Matemática. 2009. 166 f. Dissertação (Mestrado em Ensino de Ciências e Educação Matemática) - Exatas, Universidade Estadual de Londrina, Londrina, 2009.

PEPECE JUNIOR, A. R. Análise da produção escrita de estudantes da EJA em atividades algébricas. 2011. 119 f. Dissertação (Mestrado em Ensino de Ciências e Educação Matemática) - Universidade Estadual de Londrina, Londrina, 2011.

NOVAIS, P. A. F. Um estudo sobre professores de Matemática que analisam produções escritas em Grupos de Trabalho. 2017. 189 f. Dissertação (Mestrado em Educação Matemática) - Universidade Federal de Mato Grosso do Sul, Campo

20_CAPES_M

21_CAPES_D

22_CAPES_M

Grande, 2017.

23_CAPES_M

24_CAPES_M

25_CAPES_D

26_CAPES_M

27_CAPES_M

28_CAPES_M

Continua. 
Continuação.

PAIXÃO, A. C. G. Uma Prova em Fases de Matemática: da análise da produção escrita ao princípio de orientação. 2016. 103 f. Dissertação (Mestrado em Ensino de Ciências e Educação Matemática) - Universidade Estadual de Londrina, Londrina, 2016.

FERREIRA, D. de J. Uma leitura da produção de significados por uma aluna do nono ano sobre sua produção escrita em provas de Matemática. 2014. $122 \mathrm{f}$. Dissertação (Mestrado em Educação em Ciências e em Matemática) - Universidade Federal do Paraná, Curitiba, 2014.

SILVA, M. F. Tipologias discursivas à partir da produção escrita de estudantes por troca de representação de um signo artístico como indicador da aprendizagem de Sustentabilidade. 2018. 132 f. Tese (Doutorado em Ensino de Ciências e Educação Matemática) - Universidade Estadual de Londrina, Londrina, 2018.

ANDRETTA, P. Um estudo sobre desenhos infantis produzidos em situação escolar. 2013. 70 f. Dissertação (Mestrado em Ciências e em Matemática) Universidade Federal do Paraná, Curitiba, 2013.

TREVISAN, A. L. Prova em Fases e um repensar da prática avaliativa em Matemática. 2013. 160 f. Tese (Doutorado em Ensino de Ciências e Educação Matemática) - Universidade Estadual de Londrina, Londrina, 2013.

29_CAPES_M

FREITAS, B. S. P. de. Os movimentos epistêmicos e a construção de argumentos escritos em aulas de anatomia vegetal no Ensino Superior. 2017. $160 \mathrm{f}$. Dissertação (Mestrado em Ciências, com ênfase em Biologia) - Universidade de São Paulo, São Paulo, 2017.

BALLADARES, B. L. M. T. Matemática e Histórias em Quadrinhos: produção discente de HQs em uma colônia de pescadores. 2014. 184 f. Dissertação (Mestrado Profissional em Ensino de Matemática) - Universidade Federal do Rio Grande do Sul, Porto Alegre, 2014

DUARTE, R. C. Desempenho em questões de álgebra do SIMAVE sob a perspectiva dos registros de representação semiótica. 2015. 117 f. Dissertação (Mestrado em Ensino de Ciências) - Universidade Federal de São Carlos, São Carlos, 2015.

SILVA, R. A. D. da. Potencialidades e limites da Situação de Estudo para a formação pela pesquisa no ensino de Física. 2015. 154 f. Dissertação (Mestrado em Educação em Ciências: Química da Vida e Saúde) - Universidade Federal do Rio Grande do Sul, Porto Alegre, 2015.

FERNANDES. R. K. Manifestação de pensamento algébrico em registros escritos de estudantes do Ensino Funfamental I. 2014. 134 f. Dissertação (Mestrado em Ensino de Ciências e Educação Matemática) - Universidade Estadual de Londrina, Londrina, 2014.

SANTOS, G. L. dos S. Os registros de representação semiótica mobilizados por acadêmicos de um curso de Ciências Contábeis em resolução de problemas. 2014. 114 f. Tese (Doutorado em Ensino de Ciências e Educação Matemática) Universidade Estadual de Londrina, Londrina, 2014.

PORTELA, E. T. Aprendendo por meio da análise de erros: uma investigação sobre as operações com frações no estudo da Função Afim. 2018. 61 f. Dissertação (Mestrado Profissional em Matemática) - Universidade Federal de Sergipe, Itabaiana, 2018.

TOZO, F. L. D. Tarefas exploratórias-investigativas para a aprendizagem de Função Afim. 2016. 81 f. Dissertação (Mestrado em Ensino de Ciências) Universidade Federal de São Carlos, São Carlos, 2016.

XAVIER, J. V. dos S. Habilidades argumentativas de alunos do Ensino Fundamental em uma Sequência Didática argumentativa de ecologia. 2017. 220 f. Dissertação (Mestrado em Ensino de Ciências) - Universidade de São Paulo, São Paulo, 2017.

PIRES, M. N. M. Oportunidade para aprender: uma prática da reinvenção guiada na Prova em Fases. 2013. 123 f. Tese (Doutorado em Ensino de Ciências e Educação Matemática) - Universidade Estadual de Londrina, Londrina, 2013. 
Continuação.

CHIARI, A. S. A utilização do escalnamento na resolução de sistemas lineares por alunos do Ensino Médio. 2011. 142 f. Dissertação (Mestrado em Educação Matemática) - Universidade Federal de Mato Grosso do Sul, Campo Grande, 2011. PEREIRA, W. V. Propostas de utilização de Sequências Didáticas Investigativas para o estudo do conceito de velocidade no Ensino Médio. 2014. $169 \mathrm{f}$. Dissertação (Mestrado Profissional em Ensino de Física) - Universidade Federal do Espírito Santo, Vitória, 204.

SILVA, D. W. da. Conhecimentos de professores que ensinam Matemática em um Grupo de Trabalho que analisa produções escritas em Matemática. 2015. 165 f. Dissertação (Mestrado em Educação Matemática) - Universidade Federal de Mato Grosso do Sul, Campos Grande, 2015.

ALBERTONI, T. T. A Didática das Ciências na formação inicial docente: elaboração de conhecimentos sobre o Ensino de Ciências. 2015.149 f. Dissertação (Mestrado em Ensino de Ciências e Educação Matemática) - Universidade Estadual de Londrina, Londrina, 2015.

MENDES, M. T. Utilização da Prova em Fases como recurso para regulação da aprendizagem em aulas de Cálculo. 2014. 274 f. Tese (Doutorado em Ensino de Ciências e Educação Matemática) - Universidade Estadual de Londrina, Londrina, 2014.

GERETI, L. C. V. Processos do Pensamento Matemático Avançado evidenciados em resoluções de questões do Enade. 2014. 136 f. Dissertação (Mestrado em Ensino de Ciências e Educação Matemática) - Universidade Estadual de Londrina, Londrina, 2014.

PRESTES, R. F. Análise das contribuições do Educar pela Pesquisa no estudo de fontes de energia. 2008. 138 f. Dissertação (Mestrado em Educação em Ciências e Matemática) - Pontificia Universidade Católica do Rio Grande do Sul, Porto Alegre, 2008.

HILÁRIO, T. W. Vai equilibrar? As contribuições da Sequência de Ensino por Investigação para a alfabetização em linguagem no Ensino de Ciências. 2018. 159 f. Dissertação (Mestrado em Educação para Ciências e Matemática) - Instituto Federal de Educação, Ciência e Tecnologia de Goiás, Jataí, 2018.

ROCHA, C. M. S. A Revolução Científica como tema de reflexão crítica no Ensino de Física. 2018. 114 f. Dissertação (Mestrado em Ensino, História e Filosofia das Ciências e Matemática) - Universidade Federal do ABC, Santo André, 2018.

FABRICIO, M. C. A configuração de polígonos regulares e simetria na construção de mosaicos no $\mathbf{6}^{\mathbf{0}}$ ano do Ensino Fundamental. 2016. $109 \mathrm{f}$. Dissertação (Mestrado Profissional em Matemática em rede nacional) Universidade Federal de São Carlos, Sorocaba, 2016.

ALMEIDA, S. L. S. S. de. Textos de Divulgação Científica no Ensino de Biologia: possibilidades de uso da leitura para construção de conceitos em uma Unidade Didática. 2017. 156 f. Dissertação (Mestrado em Ensino de Ciências Naturais e Matemática) - Universidade Federal do Rio Grande do Norte, Natal, 2017.

SOUZA, J. S. S. de. O conceito de função: da operacionalização da definição à aprendizagem significativa. 2017. 159 f. Dissertação (Mestrado em Ensino de Ciências e Matemática) - Universidade Federal do Amazonas, Manaus, 2017.

DIAS, V. de M. T. Constituindo-se educador ambiental: um estudo das narrativas de professores que fazem educação ambiental na escola. 2012. 121 f. Dissertação (Mestrado em Educação em Ciências) - Universidade Federal do Rio Grande, Rio Grande, 2012.

SANTOS, E. S. dos. Um long play sobre formação de professores que ensinam Matemática. 2016. 142 f. Dissertação (Mestrado em Educação Matemática) Universidade Federal de Mato Grosso do Sul, Campos Grande, 2016.

JORGE, L. Na formação de professores e cientistas, uma HQ sobre aspectos da NDC e imagens: encontar-se com os entre-(em)laces. 2018. 335 f. Dissertação (Mestrado em Educação Científica e Tecnológica) - Universidade Federal de Santa Catarina, Florianópolis, 2018.

44_CAPES_M

45_CAPES_M

46_CAPES_M

47_CAPES_M

48_CAPES_D

49_CAPES_M

50_CAPES_M

51_CAPES_M

52_CAPES_M

53_CAPES_M

54_CAPES_M

55_CAPES_M

56_CAPES_M

57_CAPES_M

58_CAPES_M

Continua. 
Continuação.

BONOTTO, D .de L. (Re)configurações do agir modelagem na Formação Continuada de Professores de Matemática da Educação Básica. 2017. 310 f. Tese (Doutorado em Educação em Ciências e Matemática) - Pontificia Universidade Católica do Rio Grande do Sul, Porto Alegre, 2017.

PEREIRA, A. A. G. O Documentário de Divulgação Científica e a discussão de aspectos da Física Moderna e Contemporânea na Formação Inicial de Professores de Física. 2017. 237 f. Tese (Doutorado em Ensino de Ciências e Matemática) - Universidade Estadual de Campinas, Campinas, 2017.

NASCIMENTO, T. A. Estratégias didáticas no ensino de Ciências nos anos escolares iniciais: desafios e potencialidades na perspectiva da teoria de Lev Vygotsky. 2016. 114 f. Dissertação (Mestrado em Educação Científica e Formação de Professores) - Universidade Estadual do Sudoeste da Bahia, Jequié, 2016.

DUARTE, A. S. Metáforas criativas: processo de aprendizagem de Ciências e escrita da Língua Portuguesa como segunda Língua pelo estudante visual (surdo). 2016. 203 f. Tese (Doutorado em Ensino de Ciências e Matemática) - Universidade Federal de Mato Grosso, Cuiabá, 2016.

FRANCISCO JUNIOR, W. E. Estratégias de leitura na Educação Química e na formação docente: necessidades e contribuições de um planejamento crítico. 2011. 185 f. Tese (Doutorado em Química) - Universidade Estadual Paulista Júlio de Mesquita Filho, Araraquara, 2011.

CHAPARIN, R. O. A Formação Continuada de professores que ensinam Matemática, centrada na resolução de problemas e em processos do pensamento Matemático. 2019. 430 f. Tese (Doutorado em Educação Matemática) - Pontificia Universidade Católica de São Paulo, São Paulo, 2019.

CRUZ, I. A. da. O sol como eixo estruturante para o ensino de Física na perspectiva da Alfabetização Científica. 2019. 113 f. Dissertação (Mestrado Profissional em Ensino de Física) - Universidade Federal de Lavras, Lavras, 2019.

VALLE, M. G. do. A argumentação na produção escrita de professores de Ciências: implicações para o ensino de Genética. 2009. 99 f. Dissertação (Mestrado em Educação: Ensino de Ciências e Matemática) - Universidade de São Paulo, São Paulo, 2009.

POLICASTRO. M. S. Ressonância das aulas de Matemática: da produção escrita ao diálogo e transformação cognitiva. 2010. 136 f. Dissertação (Mestrado em em Educação: Ensino de Ciências e Matemática) - Universidade de São Paulo, São Paulo, 2010.

SILVA, M. C. N. Do observável para o oculto: Um estudo da produção escrita de alunos da $4^{\mathrm{a}}$. Série em questões de Matemática. 2005. 130 f. Dissertação (Mestrado em Ensino de Ciências e Educação Matemática) - Universidade Estadual de Londrina, Londrina, 2005.

GURGEL, I. Elementos de uma Poética da Ciência: fundamentos teóricos e implicações ao Ensino de Ciências. 2010. 301 f. Tese (Doutorado em Educação: Ensino de Ciências e Matemática) - Universidade de São Paulo, São Paulo, 2010.

LIMA, R. C. N. de. Avaliação em Matemática: análise da produção escrita de alunos da $4^{\mathrm{a}}$ série do Ensino Fundamental em questões discursivas. 2006. $201 \mathrm{f}$. Dissertação (Mestrado em em Ensino de Ciências e Educação Matemática) Universidade Estadual de Londrina, Londrina, 2006.

ALBUQUERQUE, Luciane Silva Baião de. A comunicação escrita da Ciência no espaço escolar. 2010. 225 f. Dissertação (Mestrado em Educação: Ensino de Ciências e Matemática) - Universidade de São Paulo, São Paulo, 2010.

MORAES, J. M. de. Construção dos conceitos geométricos num contexto de formação inicial de professores dos anos iniciais do Ensino Fundamental. 2008. 205 f. Dissertação (Mestrado em Educação) - Universidade de Brasília, Brasília, 2008.

NUNES, M. B. T. Uma investigação sobre o desenvolvimento da escrita em aulas de Ciências no quinto ano do Ensino Fundamental. 2013. 115 f. Dissertação (Mestrado em Educação: Educação em Ciência e Matemática) - Universidade Federal de São Carlos, São Carlos, 2013.

59_CAPES_D

60_CAPES_D

61_CAPES_M

62_CAPES_D

63_CAPES_D

64_CAPES_D

65_CAPES_M

66_IBICT_M

67_IBICT_M

68_IBICT_M

69_IBICT_D

70_IBICT_M

71_IBICT_M

72_IBICT_M

73_IBICT_M

Continua. 
Continuação.

MONTANHER, V. C. Aprendizagem Baseada em Casos nas aulas de Física do Ensino Médio. 2012. 250 f. Tese (Doutorado em Educação) - Universidade Estadual de Campinas, Campinas, 2012.

HSIA, Y. W. A utilização do livro didático pelo aluno ao estudar integral. 2006. 96 f. Dissertação (Mestrado em em Educação Matemática) - Pontificia Universidade Católica de São Paulo, São Paulo, 2006.

PEREGO, S. C. Questões abertas de Matemática: um estudo de registros escritos. 2005. 104 f. Dissertação (Mestrado em Ensino de Ciências e Educação Matemática) - Universidade Estadual de Londrina, Londrina, 2005.

MELO, N. R. V. de. Experimentos verdes em Química Orgânica: uma proposta de aplicação do método da Estrela Verde para o curso Técnico em Química. 2019. 108 f. Dissertação (Mestrado Profissional em Educação e Docência) - Universidade Federal de Minas Gerais, Belo Horizonte, 2019.

ALVES, R. M. F. Uma análise da produção escrita de alunos do Ensino Médio em questões abertas de Matemática. 2006. 158 f. Dissertação (Mestrado em Ensino de Ciências e Educação Matemática) - Universidade Estadual de Londrina, Londrina, 2006.

MENDES, I. M. Os significados do erro na práxis pedagógica da Matemática nos anos iniciais de escolarização. 2007. 147 f. Dissertação (Mestrado em Educação) - Universidade de Brasília, Brasília, 2007.

SPIELMANN, R. Usos, omissões e significados atribuídos ao sinal de igual: um olhar para a produção escrita de alunos em provas de Cálculo Diferencial Integral I. 2019. 190 f. Dissertação (Mestrado em Educação em Ciências e Educação 74_IBICT_D Matemática) - Universidade Estadual do Oeste do Paraná, Cascavel, 2019.

SEGURA, R. de O. Estudo da produção escrita de professores em questões discursivas de Matemática. 2005. 177 f. Dissertação (Mestrado em Ensino de Ciências e Educação Matemática) - Universidade Estadual de Londrina, Londrina, 2005.

PEREGO, F. O que a produção escrita pode revelar? Uma análise de questões de Matemática. 2006. 126 f. Dissertação (Mestrado em Ensino de Ciências e Educação Matemática) - Universidade Estadual de Londrina, Londrina, 2006.

75_IBICT_M

76_IBICT_M

77_IBICT_M

78_IBICT_M

79_IBICT_M

80_IBICT_M 81_M 